\title{
Three-Dimensional Cobalt Hydroxide Hollow Cube/Vertical Nanosheets with High Desalination Capacity and Long-Term Performance Stability in Capacitive Deionization
}

\author{
Yuecheng Xiong $\mathbb{D},{ }^{1,2}$ Fei Yu, ${ }^{3}$ Stefanie Arnold $\mathbb{D},{ }^{4,5}$ Lei Wang $\mathbb{D}^{4,5}$ Volker Presser $\mathbb{D}^{4,4,6}$ \\ Yifan Ren, ${ }^{1,2}$ and Jie Ma $\oplus^{1,2,7}$ \\ ${ }^{1}$ State Key Laboratory of Pollution Control and Resource Reuse, College of Environmental Science and Engineering, \\ Tongji University, Shanghai 200092, China \\ ${ }^{2}$ Research Center for Environmental Functional Materials, College of Environmental Science and Engineering, Tongji University, \\ 1239 Siping Road, Shanghai 200092, China \\ ${ }^{3}$ College of Marine Ecology and Environment, Shanghai Ocean University, Shanghai 201306, China \\ ${ }^{4}$ INM-Leibniz Institute for New Materials, 66123 Saarbrücken, Germany \\ ${ }^{5}$ Department of Materials Science and Engineering, Saarland University, 66123 Saarbrücken, Germany \\ ${ }^{6}$ Saarene-Saarland Center for Energy Materials and Sustainability, 66123 Saarbrücken, Germany \\ ${ }^{7}$ Shanghai Institute of Pollution Control and Ecological Security, Shanghai 200092, China
}

Correspondence should be addressed to Jie Ma; jma@tongii.edu.cn

Received 4 August 2021; Accepted 29 September 2021; Published 26 October 2021

Copyright (c) 2021 Yuecheng Xiong et al. Exclusive Licensee Science and Technology Review Publishing House. Distributed under a Creative Commons Attribution License (CC BY 4.0).

Faradaic electrode materials have significantly improved the performance of membrane capacitive deionization, which offers an opportunity to produce freshwater from seawater or brackish water in an energy-efficient way. However, Faradaic materials hold the drawbacks of slow desalination rate due to the intrinsic low ion diffusion kinetics and inferior stability arising from the volume expansion during ion intercalation, impeding the engineering application of capacitive deionization. Herein, a pseudocapacitive material with hollow architecture was prepared via template-etching method, namely, cuboid cobalt hydroxide, with fast desalination rate $\left(3.3 \mathrm{mg}(\mathrm{NaCl}) \cdot \mathrm{g}^{-1}\left(\mathrm{~h}-\mathrm{Co}(\mathrm{OH})_{2}\right) \cdot \mathrm{min}^{-1}\right.$ at $\left.100 \mathrm{~mA} \cdot \mathrm{g}^{-1}\right)$ and outstanding stability $(90 \%$ capacity retention after 100 cycles). The hollow structure enables swift ion transport inside the material and keeps the electrode intact by alleviating the stress induced from volume expansion during the ion capture process, which is corroborated well by in situ electrochemical dilatometry and finite element simulation. Additionally, benefiting from the elimination of unreacted bulk material and vertical cobalt hydroxide nanosheets on the exterior surface, the synthesized material provides a high desalination capacity $\left(117 \pm 6 \mathrm{mg}(\mathrm{NaCl}) \cdot \mathrm{g}^{-1}\left(\mathrm{~h}-\mathrm{Co}(\mathrm{OH})_{2}\right)\right.$ at $\left.30 \mathrm{~mA} \cdot \mathrm{g}^{-1}\right)$. This work provides a new strategy, constructing microscale hollow faradic configuration, to further boost the desalination performance of Faradaic materials.

\section{Introduction}

The recent two decades have witnessed soaring population growth, freshwater consumption, and global climate change, and ubiquitous pollution exacerbates freshwater deficiency $[1,2]$. Therefore, scientists seek opportunities to produce usable water from inexhaustible seawater through desalination. Traditional desalination technologies, such as thermal distillation, reverse osmosis, and electrodialysis, exert heat, pressure, or electricity to extract water, which is highly energy-intensive [3]. Newly emerging processes, including capacitive deionization and membrane solar distillation, create less carbon footprint [4]. Capacitive deionization separates charged ions from saline media via electrosorption; the low applied cell voltage and high charge efficiency render this technique very promising regarding desalination of brackish water [5]. Distillation induced by concentrated solar radiation is intriguing because no external energy input is needed, but the freshwater production rate cannot meet large-scale production demand [6]. Therefore, capacitive deionization is attractive as an alternative energy-efficient desalination technique. 
Electrodes are the core component of electrochemical desalination and ion separation. Typical electrodes can be divided into carbon electrodes and charge-transfer electrodes depending on the absence or presence of redox processes [7]. Ion intercalation or conversion reactions (charge-transfer materials) enable a much higher desalination capacity than possible for carbon-based electrodes because of the higher charge storage capacity and perm-selectivity; thereby, they enable facile desalination even at high molar strength. Currently, various charge-transfer materials for electrochemical desalination have been reported, such as transition metal oxides $\left(\mathrm{MnO}_{2}, \mathrm{TiO}_{2}, \mathrm{~V}_{2} \mathrm{O}_{5}\right.$, and $\left.\mathrm{ZnFe}_{2} \mathrm{O}_{4}\right)$ [8-11], Prussian blue analogs (nickel hexacyanoferrate) [12-14], polyanionic phosphates $\left(\mathrm{Na}_{3} \mathrm{~V}_{2}\left(\mathrm{PO}_{4}\right)_{3}, \quad \mathrm{Na}_{3} \mathrm{Ti}_{2}\left(\mathrm{PO}_{4}\right)_{3}\right)$ [15-17], and two-dimensional materials (MXenes, $\mathrm{MoS}_{2}$, and $\mathrm{TiS}_{2}$ ) [18-22]. Among these materials, metal oxides or hydroxides hold the advantages of easy preparation, facile morphological manipulation, element diversity, and promising desalination performance. Yet, charge-transfer materials usually show a tradeoff between high capacity and good stability [23]. Theoretically, higher capacity means that more ions are removed, which generally causes more obvious volume changes. The performance degrades irreversibly if the material cannot relieve the accompanying stress [24]. For example, the lithiation of transition metal oxides (such as $\mathrm{Fe}_{2} \mathrm{O}_{3}, \mathrm{Co}_{3} \mathrm{O}_{4}$, and $\mathrm{NiO}$ ) induces near $100 \%$ volume expansion in lithium-ion batteries, severely deteriorating the energy storage performance [25].

Stability is a vital characteristic of desalination electrodes. High stability means longer service life and more desalination cycles, which can decrease the cost of material and operation; meanwhile, less need for material signifies less solid waste produced, avoiding extra posttreatment costs. The chemical stability ensures that no toxic heavy metal ions $\left(\mathrm{Mn}^{2+}, \mathrm{V}^{5+}, \mathrm{Co}^{2+}\right.$, etc.) from electrode materials leach into treated water, which is key to safe water quality. Therefore, electrode materials with good stability and reliability are crucial for desalination application.

The critical importance of performance stability can be addressed by designing flexible three-dimensional scaffolds to support Faradaic materials. For example, interconnected carbon networks and polymer hydrogel serve as structural support and pathways for electron transport [26]. $\mathrm{Na}_{3} \mathrm{~V}_{2}\left(\mathrm{PO}_{4}\right)_{3}$ /graphene hybrid aerogel exhibits a high capacity of about $100 \mathrm{mg} \cdot \mathrm{g}^{-1}$ after 50 cycles in a dualion deionization system but inferior stability than pure aerogel [26]. ZIF-67/PPy hybrid materials display stable desalination performance with a capacity of $11 \mathrm{mg}^{-1} \mathrm{~g}^{-1}$ for $200 \mathrm{~h} \mathrm{[27].}$ However, the conductive network's cushion effect cannot enhance the intrinsic stability of charge-transfer materials, and simultaneous high capacity and good stability cannot be realized because supporting materials usually have lower desalination performance. Therefore, regulating the microscale or nanoscale structure of the Faradaic electrode materials will offer opportunities to further enhance the deionization performance instead of focusing on carbon-faradaic composite materials.

Constructing a hollow structure with lightweight architecture for pseudocapacitive materials is an appealing tactic to simultaneously achieve superior capacity and stability. A hollow configuration provides ample space for volume change, which has been widely applied in catalysis to strengthen the efficiency and cycling performance [28]. A hollow structure reduces the proportion of dead mass, which is the unreacted bulk of the material, thus improving the desalination capacity. Besides, hollow structures can ensure sufficient contact between electrode and electrolyte due to both inner and outer surfaces, providing more available active sites and enhancing the ion transport kinetics. An open graphene structure has been proposed for electrochemical desalination recently, but the inherent weakness of carbon materials restricts the performance [29]. Hollow charge-transfer electrode materials can break the tradeoff between high capacity and stable cycling, which is an appealing strategy to overcome shortcomings in capacitive deionization (low desalination capacity, low desalination rate, and poor stability) at a time.

Here, we synthesized a hollow transition hydroxide, cuboid cobalt hydroxide, with well-arranged nanosheets on its surface via template etching. $\mathrm{Co}(\mathrm{OH})_{2}$ exhibits substantial pseudocapacitance, widely utilized in the energy storage field $[30,31]$. Amorphous $\mathrm{Co}(\mathrm{OH})_{2}$ nanocages or nanoboxes have also been used in batteries and catalytic water splitting, which employ similar electrochemical processes as electrochemical desalination $[32,33]$. In our work, we show that cobalt hydroxide with optimized morphology provides a high desalination capacity of $117 \pm 6 \mathrm{mg}(\mathrm{NaCl}) \cdot \mathrm{g}^{-1}$ $\left(\mathrm{h}-\mathrm{Co}(\mathrm{OH})_{2}\right)$ and a fast desalination rate of $3.3 \mathrm{mg}$ $(\mathrm{NaCl}) \cdot \mathrm{g}^{-1}\left(\mathrm{~h}-\mathrm{Co}(\mathrm{OH})_{2}\right) \cdot \mathrm{min}^{-1}$. The cobalt hydroxide electrodes exhibit excellent stability without the coupling of three-dimensional supporting networks. This paper offers a new strategy to elevate the desalination rate and strengthen the stability through the hollow structure without sacrificing the high capacity of faradic electrodes, showing the promising application in large-scale CDI.

\section{Materials and Methods}

2.1. Preparation of the $\mathrm{Cu}_{2} \mathrm{O}$ Template. All chemicals and reagents were purchased from Sinopharm Chemical Reagent Co., Ltd, and used without further purification. $\mathrm{CuCl}_{2} \cdot 2 \mathrm{H}_{2} \mathrm{O}$ $(10 \mathrm{mM}, 100 \mathrm{~mL})$ was heated in a $55^{\circ} \mathrm{C}$ water bath under magnetic stirring, and then, $\mathrm{NaOH}(2 \mathrm{M}, 10 \mathrm{~mL})$ was added slowly. The color of the solution changed from dusty aquamarine to dark brown. $30 \mathrm{~min}$ later, freshly prepared ascorbic acid $(0.6 \mathrm{M}, 10 \mathrm{~mL})$ was added dropwise by a syringe, and the solution appeared brownish-black, turning into brick red in the end. After continuous agitation for $3 \mathrm{~h}$, the $\mathrm{Cu}_{2} \mathrm{O}$ template was separated by vacuum filtration and washed with deionized water and ethanol several times. The sample was acquired after $60^{\circ} \mathrm{C}$ of vacuum drying for $5 \mathrm{~h}$.

\subsection{Preparation of Hollow $\mathrm{Co}(\mathrm{OH})_{2}$ Cube/Vertical Nanosheets.} $100 \mathrm{mg} \mathrm{Cu}_{2} \mathrm{O}$ powder was added into a mixed solution of $100 \mathrm{~mL}$ deionized water plus $100 \mathrm{~mL}$ ethanol, and the mixture was ultrasonicated for $1 \mathrm{~h}$. The remaining steps were conducted under $500 \mathrm{rpm}$ magnetic stirring. $6.6 \mathrm{~g}$ 
polyvinylpyrrolidone K30 (PVP-K30) was added. After $30 \mathrm{~min}$, $60 \mathrm{mg} \mathrm{CoCl}_{2} \cdot 6 \mathrm{H}_{2} \mathrm{O}$ was added. Another $30 \mathrm{~min}$ later, $\mathrm{Na}_{2} \mathrm{~S}_{2} \mathrm{O}_{3}(1 \mathrm{M}, 100 \mathrm{~mL})$ was added dropwise by a peristaltic pump with a controlled rate of one drop per second. When the solution turned into jade green, the hollow cube cobalt hydroxide material was obtained after vacuum filtration, cleaning, and drying at $40^{\circ} \mathrm{C}$ overnight. Regarding our manuscript, we refer to hollow $\mathrm{Co}(\mathrm{OH})_{2}$ cube as "h- $\mathrm{Co}(\mathrm{OH})_{2}$."

2.3. Electrode Preparation. The active materials $\left(\mathrm{Co}(\mathrm{OH})_{2}\right.$ powder or activated carbon) were mixed with a conductive additive (acetylene black) and binder (polyvinylidene difluoride, PVDF) at a mass ratio of $8: 1: 1$. Afterward, 1-methyl-2-pyrrolidinone (NMP) was added appropriately, and the mixture was stirred overnight to form a homogeneous and viscous paste. Then, electrodes were prepared by the doctor-blade method on graphite paper with a thickness of ca. $75 \mu \mathrm{m}$. Next, prepared electrodes were dried at $40^{\circ} \mathrm{C}$ under vacuum for $12 \mathrm{~h}$ to remove any residual organic solvent. The electrode's mass was determined by the difference between pure graphite paper and dried electrode, and the electrode mass used for electrochemical desalination was about $4.0 \mathrm{mg}$.

2.4. Electrochemical Characterization. All electrochemical characterization, including cyclic voltammetry (CV), galvanostatic charging/discharging cycling (GCD), and electrochemical impedance spectroscopy (EIS), was conducted by the electrochemical station (CHI660D, Shanghai Chenhua Instruments Co.) in a three-electrode cell with $1 \mathrm{M} \mathrm{NaCl}$ as the electrolyte. Electrodes of $1 x 1 \mathrm{~cm}^{2}$ were used as the working electrode, while $\mathrm{Pt}$ and $\mathrm{Ag} / \mathrm{AgCl}$ were employed as the counter electrode and reference electrode, respectively. Cyclic voltammetry was swept between $-0.6 \mathrm{~V}$ and $+0.6 \mathrm{~V}$ under various scan rates $\left(1-50 \mathrm{mV} \cdot \mathrm{s}^{-1}\right)$, and GCD was tested under the same voltage window with different specific currents $\left(0.1-2 \mathrm{~A} \cdot \mathrm{g}^{-1}\right)$. The EIS spectra were recorded over the frequency range of $10^{5} \mathrm{~Hz}$ to $10^{-2} \mathrm{~Hz}$ with an amplitude of $5 \mathrm{mV}$. Besides, CV and GCD were also carried out in a two-electrode cell with a working electrode and an oversized activated carbon powder (400 mesh, Macklin) electrode as the counter electrode in $1 \mathrm{M} \mathrm{NaCl}$.

In situ electrochemical dilatometry was performed in an ECD-3 nanoelectrochemical dilatometer (EL-CELL) to track the volume changes during cyclic voltammetry by constructing a two-electrode cell (h- $\mathrm{Co}(\mathrm{OH})_{2}$ versus carbon) with an oversized activated carbon (90 mass\% YP-80F, 10 mass $\%$ polymer binder) as counter- and quasireference electrode in $1 \mathrm{M} \mathrm{Na}_{2} \mathrm{SO}_{4}$. All cell parts were dried overnight at $80^{\circ} \mathrm{C}$ and introduced into an argon-filled glovebox (MBraun Labmaster 130; $\left.\mathrm{O}_{2} ; \mathrm{H}_{2} \mathrm{O}<0.1 \mathrm{ppm}\right)$. h- $\mathrm{Co}(\mathrm{OH})_{2}$ electrode was drop-casted on a $\mathrm{Pt}$ disc with a diameter of $10 \mathrm{~mm}$, and the initial thickness was $65 \mu \mathrm{m}$. All electrochemical measurements were carried out at a climate chamber (Binder) with a constant temperature of $25 \pm 1^{\circ} \mathrm{C}$. Cyclic voltammetry (CV) measurements were carried out using a VMP3 multichannel potentiostat/galvanostat from Bio-Logic (France). After a resting period and stabilization time of $48 \mathrm{~h}$ or $72 \mathrm{~h}$, cyclic voltammograms were recorded at $1 \mathrm{mV} \mathrm{s}^{-1}$ in the range of $-0.8 \mathrm{~V}$ to $+0.3 \mathrm{~V}$ vs. carbon.

2.5. Electrochemical Desalination Performance. The flow-by capacitive deionization device consists of the following parts: acrylic plates, silicone gaskets, electrodes, cation/anion exchange membranes, and a chamber with the dimension of $2 \times 2 \times 1 \mathrm{~cm}^{3}$. The whole testing system is composed of a power source (LAND battery testing system), deionization apparatus, peristaltic pump, $\mathrm{NaCl}$ solution tank, and conductivity meter (Mettler Toledo S230). All deionization tests were done in constant current operation and batch mode. The $\mathrm{NaCl}$ solution volume was $25 \mathrm{~mL}$, and the flow rate was fixed at $15 \mathrm{~mL} \cdot \mathrm{min}^{-1}$. Other parameters, including cutoff voltage $( \pm 0.6 \mathrm{~V}, \pm 0.8 \mathrm{~V}, \pm 1.0 \mathrm{~V}, \pm 1.2 \mathrm{~V}, \pm 1.4 \mathrm{~V}$, and $\pm 1.6 \mathrm{~V})$, initial feed concentration (10 mM, $100 \mathrm{mM}$, and $600 \mathrm{mM})$, and specific current $\left(30-100 \mathrm{~A} \cdot \mathrm{g}^{-1}\right)$, were adjusted to acquire the optimized performance and investigate the desalination mechanism. The deionization capacity was calculated based on the relationship between conductivity and concentration and is presented in the following equation:

$$
\text { Deionization capacity } Q=\frac{\left(C_{i}-C_{f}\right) V}{m}\left(\frac{\mathrm{mg}_{\mathrm{NaCl}}}{\mathrm{g}_{\mathrm{h}-\mathrm{Co}(\mathrm{OH})_{2}}}\right) \text {, }
$$

where $C_{i}$ and $C_{f}\left(\mathrm{mg} \cdot \mathrm{L}^{-1}\right)$ are the concentration of $\mathrm{NaCl}$ before and after deionization, respectively; $V(25 \mathrm{~mL})$ is the volume of $\mathrm{NaCl}$ solution; and $m(\mathrm{mg})$ is the total mass of $\mathrm{Co}(\mathrm{OH})_{2}$ electrode containing conductive additive and binder.

2.6. Material Characterization. The formation process and surface morphology of hollow $\mathrm{Co}(\mathrm{OH})_{2}$ were characterized by scanning electron microscopy (SEM, Hitachi S-4800) and transmission electron microscopy (TEM, JEOL-2010F). The crystal structure was analyzed using X-ray diffraction (XRD D8 ADVANCE, Bruker AXS) operated at $40 \mathrm{~mA}$ and $45 \mathrm{kV}$ with $\mathrm{Cu}-\mathrm{K} \alpha$ radiation $\left(\lambda=0.154 \mathrm{~nm}, 5^{\circ} / \mathrm{min}\right)$. $\mathrm{X}$-ray photoelectron spectroscopy (XPS) analysis was carried out in a ThermoFisher ESCALAB 250Xi spectrometer using $\mathrm{Al}-\mathrm{K} \alpha$ radiation $(1486.6 \mathrm{eV})$ with a base pressure of $1 \times 10^{9}$ torr. The peak energies were calibrated by $\mathrm{C} 1 \mathrm{~s}$ peak at $284.8 \mathrm{eV}$. The wettability was reflected by the water contact angle (POWEREACH JC2000D2W). Raman spectra were recorded with a Renishaw inVia system using an Nd:YAG laser with an excitation wavelength of $532 \mathrm{~nm}$. The spectral resolution was $1.2 \mathrm{~cm}^{-1}$, and the diameter of the laser spot on the sample was around $2 \mu \mathrm{m}$ with a total power exposure of $0.5 \mathrm{~mW}$. The exposure time is $30 \mathrm{~s}$ with 5 accumulations. The numeric aperture was 0.75 . The specific surface area and pore size distribution were calculated from the adsorption/desorption isotherms of $\mathrm{N}_{2}$ at $-196^{\circ} \mathrm{C}$ by the multipoint BET and BJH method using a BELSORP Max instrument $(\mathrm{BEL})$, and the sample was degassed at $120^{\circ} \mathrm{C}$ for $6 \mathrm{~h}$ before the measurements. The 2D-NLDFT analysis was carried out with SAIEUS assuming finite pores with an aspect ratio of 6 and using a regularization parameter of 2.75 . 


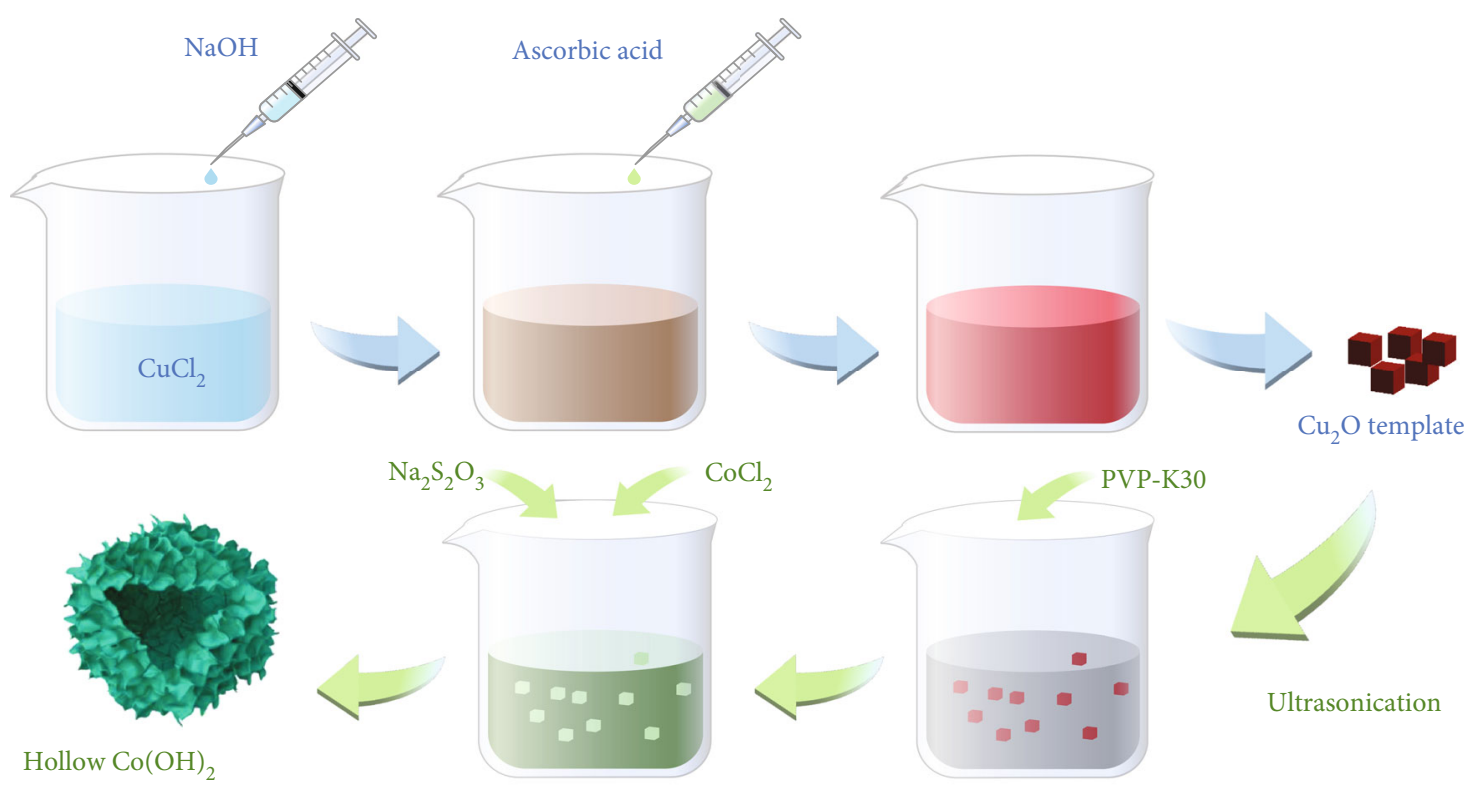

(a)

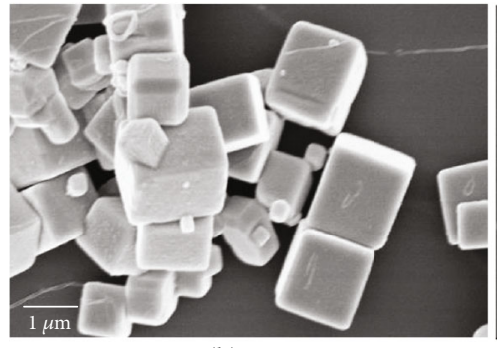

(b)

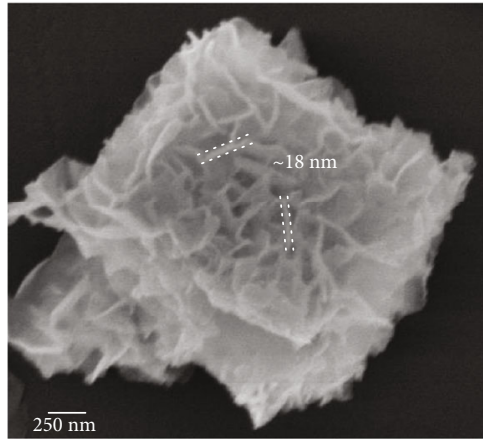

(e)

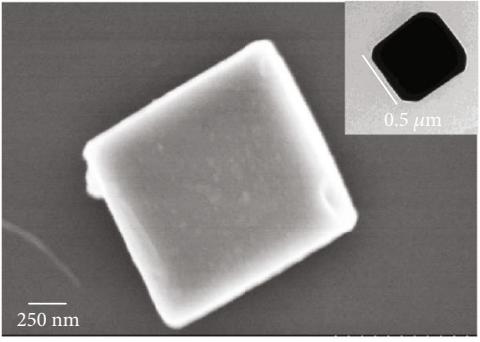

(c)

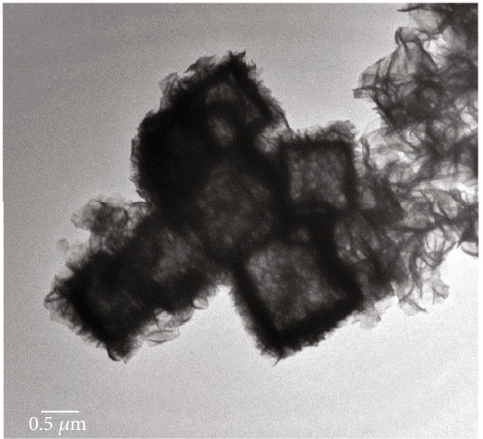

(f)

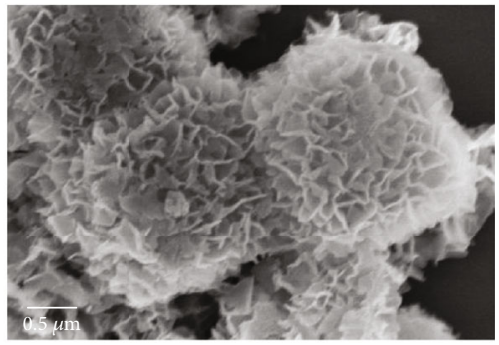

(d)

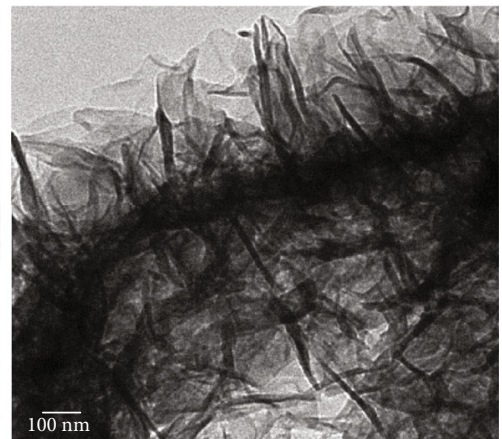

(g)

FIgure 1: (a) Schematic illustration of the hollow $\mathrm{Co}(\mathrm{OH})_{2}$ cube preparation. Scanning electron micrographs of the $\mathrm{Cu}_{2} \mathrm{O}(\mathrm{b}, \mathrm{c})(\mathrm{inset}$ in $(\mathrm{c})$ is the transmission electron micrograph of $\mathrm{Cu}_{2} \mathrm{O}$ cube) and hollow $\mathrm{Co}(\mathrm{OH})_{2}$ cube $(\mathrm{d}, \mathrm{e})$. Transmission electron micrographs of the hollow $\mathrm{Co}(\mathrm{OH})_{2}$ cube (f, g).

\section{Results and Discussion}

3.1. Material Characterization. Hollow $\mathrm{Co}(\mathrm{OH})_{2}$ cube was synthesized via classical coordination etching and precipitation process guided under Pearson's hard and soft acid-base principle $[34,35]$, with the schematic illustration shown in Figure 1(a).

First, the $\mathrm{Cu}_{2} \mathrm{O}$ sacrificial template was prepared by precipitation and reduction reaction, exhibiting a cubic shape with a side length of $0.5 \mu \mathrm{m}$ to $1 \mu \mathrm{m}$ (Figure $1(\mathrm{~b})$ ), and the surface of the $\mathrm{Cu}_{2} \mathrm{O}$ cube is relatively smooth (Figure $1(\mathrm{c})$ ).
Afterward, $\mathrm{Na}_{2} \mathrm{~S}_{2} \mathrm{O}_{3}$ was used to etch the precursor and release $\mathrm{OH}^{-}$to create an alkaline environment, whereby cobalt hydroxide was precipitated synchronously. The simultaneous etching and $\mathrm{Co}(\mathrm{OH})_{2}$ growing process is verified by time-dependent TEM images (Supporting Information, Fig. S1). The appearance of cobalt hydroxide is cuboid with an apparent hollow structure (Figure 1(f)). Some individual cubes are broken, which exposes the interior surface and shortens the ion transport distance during electrochemical operation. Thin cobalt hydroxide nanosheet arrays with a thickness of around $18 \mathrm{~nm}$ extend from the 


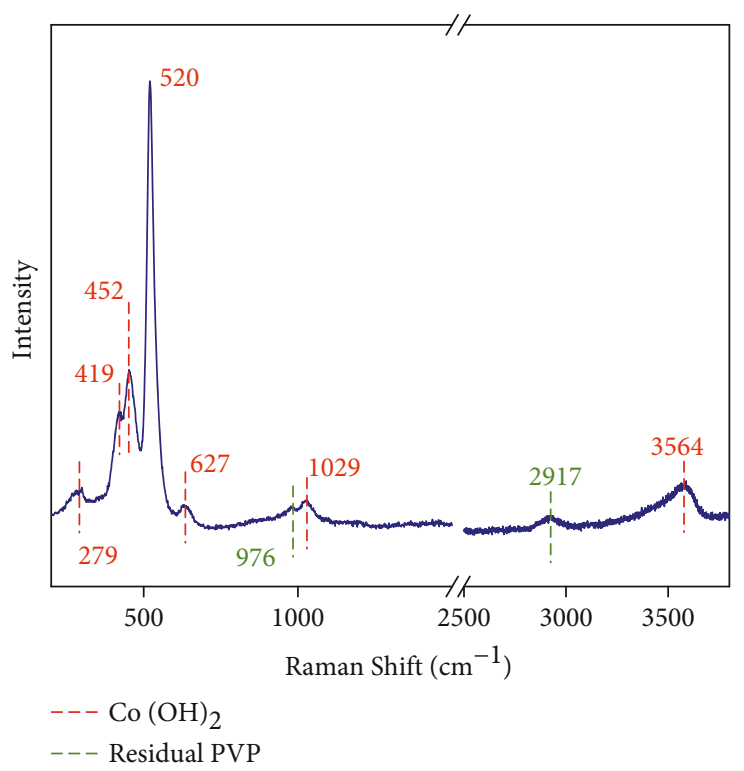

(a)

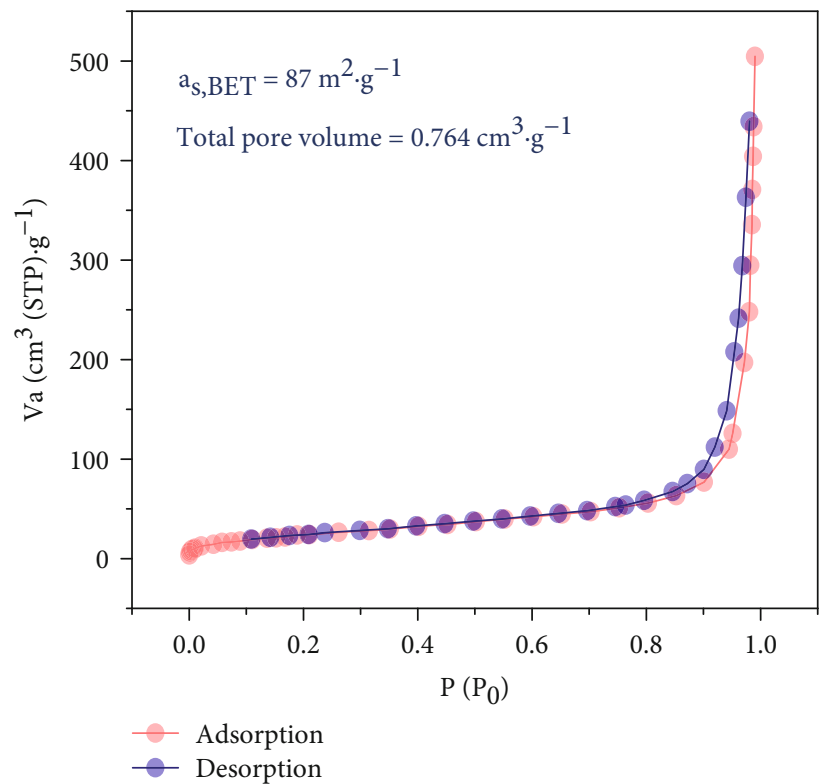

(c)

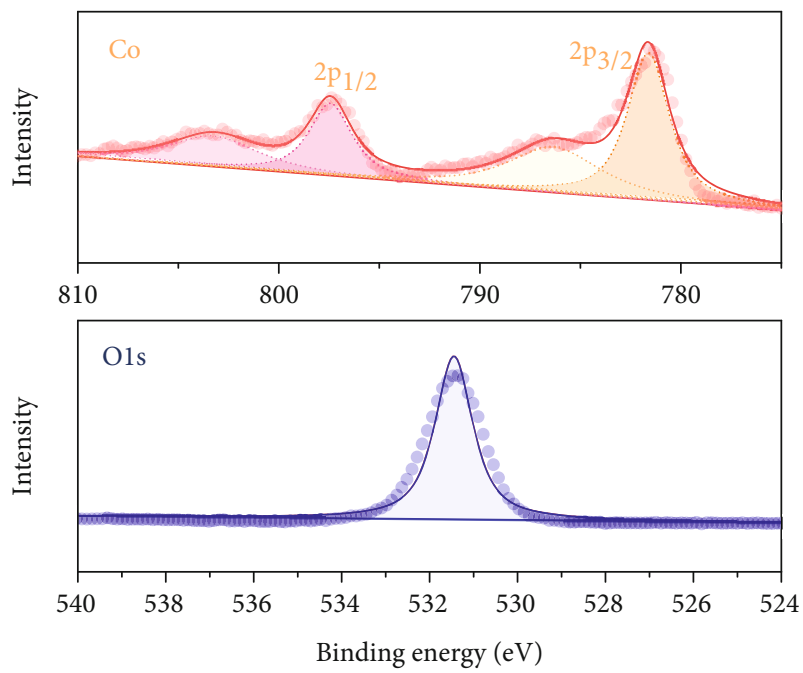

(b)

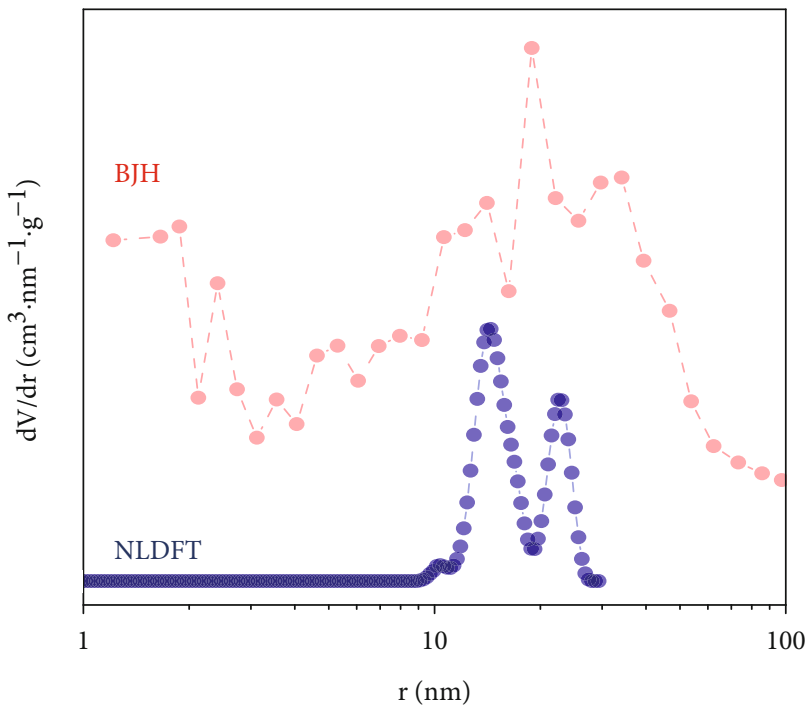

(d)

Figure 2: Characterization data of hollow $\mathrm{Co}(\mathrm{OH})_{2}$ cubes: Raman spectrum (a), X-ray photoelectron spectra of Co 2p and $\mathrm{O} 1 \mathrm{~s}(\mathrm{~b}), \mathrm{N}_{2}$ adsorption/desorption isotherm measured at $-196^{\circ} \mathrm{C}(\mathrm{c})$, and pore size distribution based on BJH and NLDFT models (d).

shell, providing abundant sites for ions to be reacted and stored (Figures 1(d), 1(e), and 1(g)).

The successful synthesis of cobalt hydroxide in the form of $\mathrm{Co}(\mathrm{OH})_{2}$ was confirmed by Raman spectroscopy (Figure 2(a)). The peak at 279, 419, 452, 520, 1029, and $3564 \mathrm{~cm}^{-1}$ belongs to $\mathrm{Co}(\mathrm{OH})_{2}[36,37]$; among them, the band at $520 \mathrm{~cm}^{-1}$ attributes to the $\mathrm{CoO}\left(\mathrm{A}_{\mathrm{g}}\right)$ symmetric stretching mode; the bands at $452 \mathrm{~cm}^{-1}$ and $3564 \mathrm{~cm}^{-1}$ are assigned to the $\mathrm{OCoO}$ bending mode [37] and $\mathrm{OH}$ vibrational mode [38], respectively. The peak at $627 \mathrm{~cm}^{-1}$ corresponds to the $\mathrm{F}_{\mathrm{g}}^{22}$ of $\mathrm{Co}_{3} \mathrm{O}_{4}$ or belongs to $\mathrm{Co}(\mathrm{OH})_{2}$ [39], while the bonds at $976 \mathrm{~cm}^{-1}$ and $2917 \mathrm{~cm}^{-1}$ possibly arise from the remaining PVP $[40,41]$. Besides, none of the characteristic reflections for $\mathrm{CoO}$ are found after $40^{\circ} \mathrm{C}$ vacuum drying. Based on the XPS results (Figure 2(b)), the prominent peak of Co $2 \mathrm{p}_{3 / 2}$ locates at around $781.5 \mathrm{eV}$ with a satellite peak ca. $5 \mathrm{eV}$ away. This spectral data verifies the existence of $\mathrm{Co}^{2+}$, which is further corroborated by a single peak of $\mathrm{O}$ $1 \mathrm{~s} \mathrm{spectra}$ at approximately $531.4 \mathrm{eV}$. [42] Despite no subpeak for hydroxyls, the hydrophilicity of $\mathrm{Co}(\mathrm{OH})_{2}$ electrode is verified by decreasing water contact angle with time. After desalination, a contact angle of $54.40^{\circ}$ was measured (Supporting Information, Fig. S2).

$\mathrm{N}_{2}$ adsorption/desorption isotherms show the type $\mathrm{V}$ curve, indicating no micropore but mesopore structure exists in h-Co(OH $)_{2}$, and a type $\mathrm{H} 3$ hysteresis loop suggests 

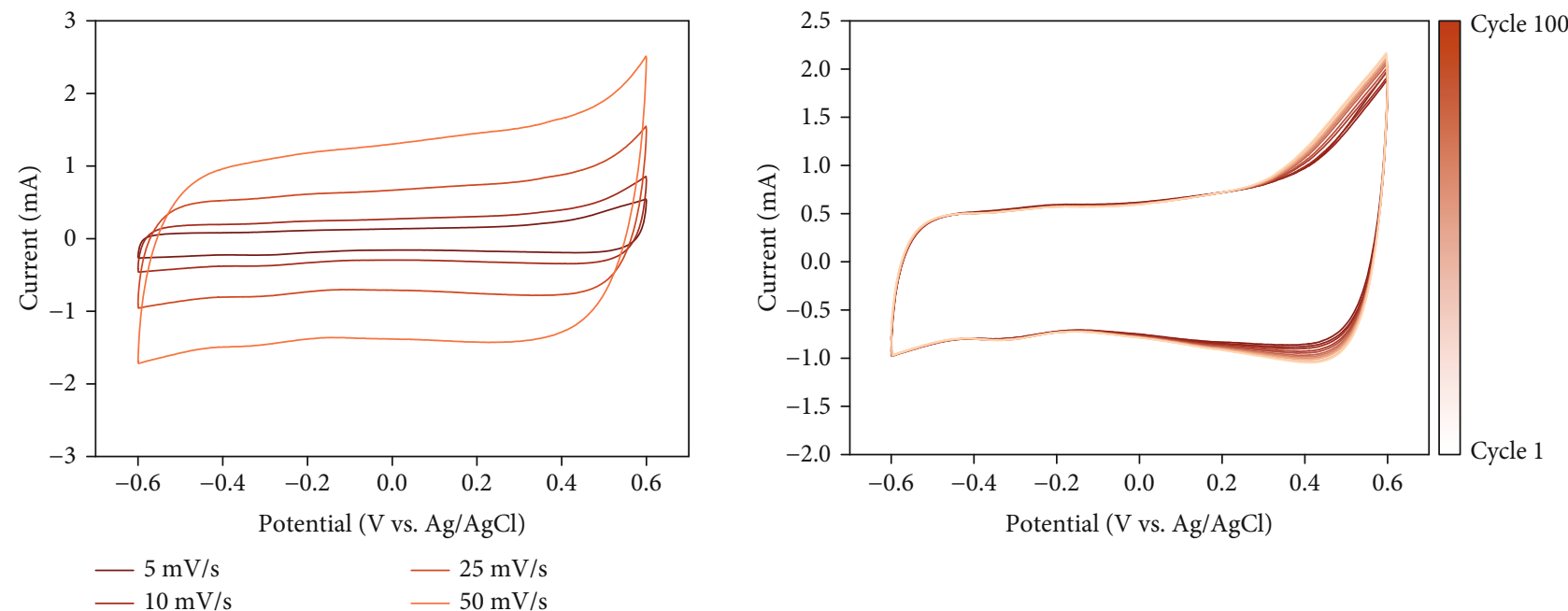

(a)

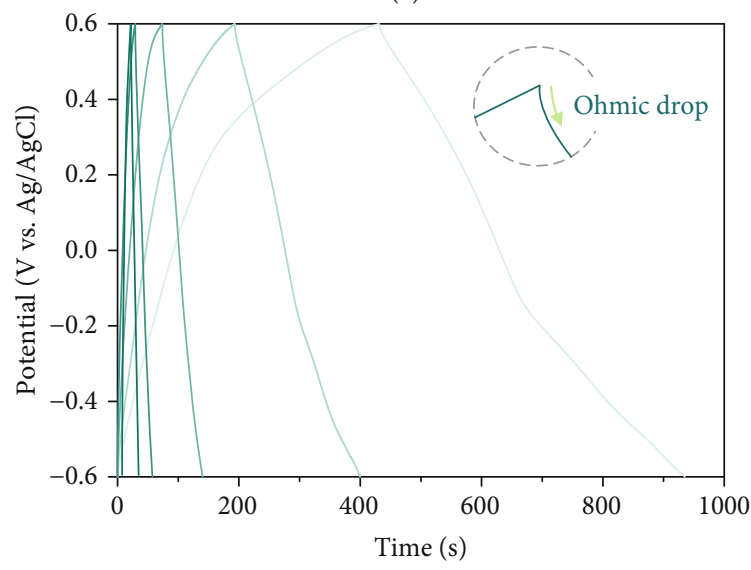

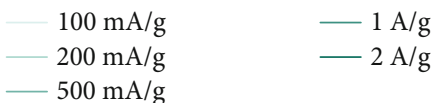

(c) (b)

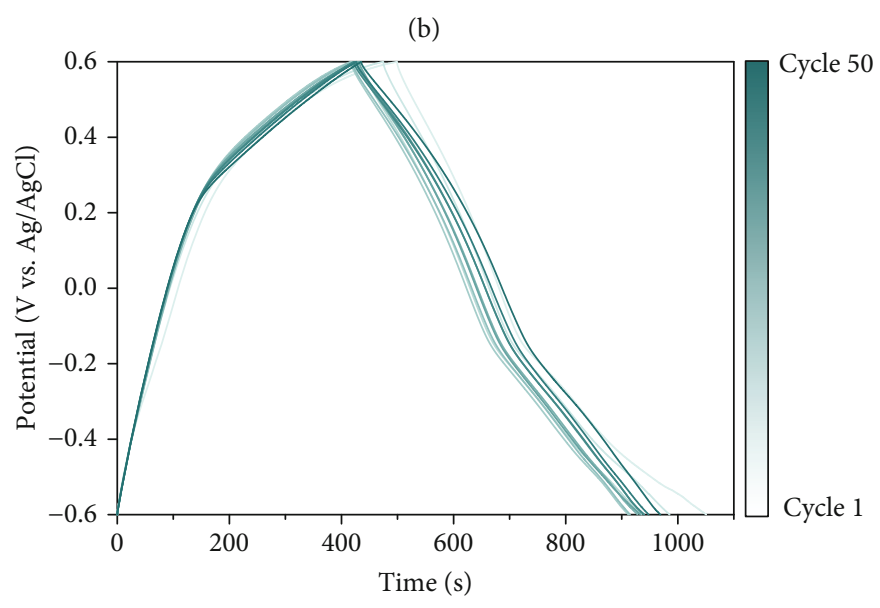

(d)

Figure 3: (a) Cyclic voltammograms of the hollow $\mathrm{Co}(\mathrm{OH})_{2}$ cube at different scan rates. (b) 100 cyclic voltammetry cycling curves at $25 \mathrm{mV} \cdot \mathrm{s}^{-1}$. (c) Galvanostatic charging/discharging profiles of the hollow $\mathrm{Co}(\mathrm{OH})_{2}$ cube at different specific currents. (d) 50 galvanostatic charging/discharging cycling profiles at $100 \mathrm{~mA} \cdot \mathrm{g}^{-1}$.

slit pore geometry created by the stacking of flake particles (Figure 2(c)). The specific surface area of the $\mathrm{Co}(\mathrm{OH})_{2}$ cube determined by the Brunauer-Emmett-Teller (BET) method is about $87 \mathrm{~m}^{2} \cdot \mathrm{g}^{-1}$, and the mean pore radius derived from the Barrett-Joyner-Halenda (BJH) and NLDFT (2D-NLDFT finite pores were assumed) models is about $20 \mathrm{~nm}$. Such large mesopores are expected to yield sufficient space for ion transport pathways during electrochemical desalination (Figure 2(d)).

3.2. Electrochemical Performance. The cyclic voltammogram of h-Co(OH $)_{2}$ presents a quasirectangular shape without observable redox peaks (Figure 3(a)). This specific shape indicates that $\mathrm{h}-\mathrm{Co}(\mathrm{OH})_{2}$ is a pseudocapacitive material like other transition metal oxides and hydroxides corroborated by GCD profiles without plateau (Figure 3(c)). A pair of shallow peaks at around $-0.3 \mathrm{~V}$ and $-0.1 \mathrm{~V}$ is evident at a rate of $1 \mathrm{mV} \cdot \mathrm{s}^{-1}$ (Supporting Information, Fig. S3), which aligns with the pseu- docapacitive property due to the small $\Delta V$ between redox peaks [43]. Besides, the thin-film electrode is prone to be pseudocapacitive as a result of free ion diffusion [44]. This aligns with the open (hollow) architecture and short diffusion paths within $\mathrm{h}-\mathrm{Co}(\mathrm{OH})_{2}$. The capacitance values calculated from different scan rates $\left(5-50 \mathrm{mV} \cdot \mathrm{s}^{-1}\right)$ are 32 $24 \mathrm{~F} \cdot \mathrm{g}^{-1}$. The slight loss of capacitance at a high scan rate demonstrates the rapid charge storage mechanism.

The h-Co(OH $)_{2}$ electrode shows very good performance stability, characterized by repeated cyclic voltammetry and galvanostatic charge/discharge cycling. The cyclic voltammograms' shapes display no significant change after 100 cycles except minor alteration at $+0.4 \mathrm{~V}$ to $+0.6 \mathrm{~V}$ (vs. $\mathrm{Ag} / \mathrm{AgCl}$ ). Hence, h- $\mathrm{Co}(\mathrm{OH})_{2}$ might experience side reactions at a voltage beyond $+0.4 \mathrm{~V}$ (Figure $3(\mathrm{~b})$ ). The performance from GCD profiles degrades slightly at first and returns to the original level, and the retention proportion for charging capacity is 97\% after 50 cycles (Figure 3(d)). 


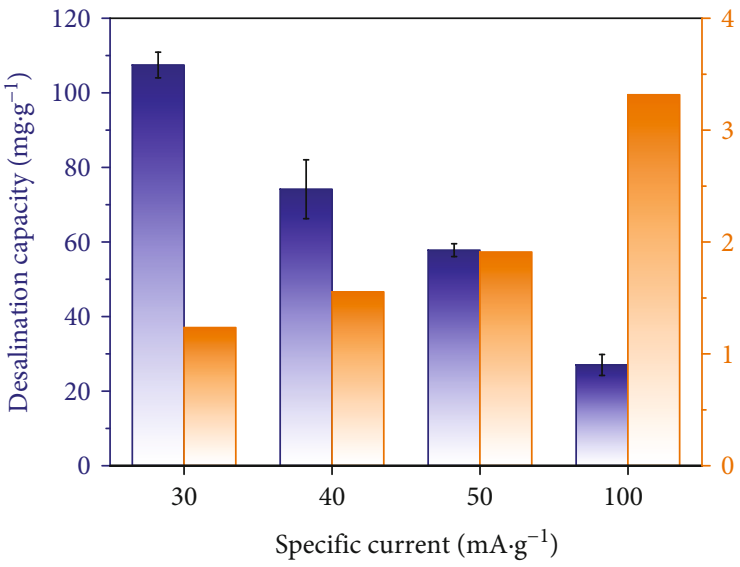

(a)

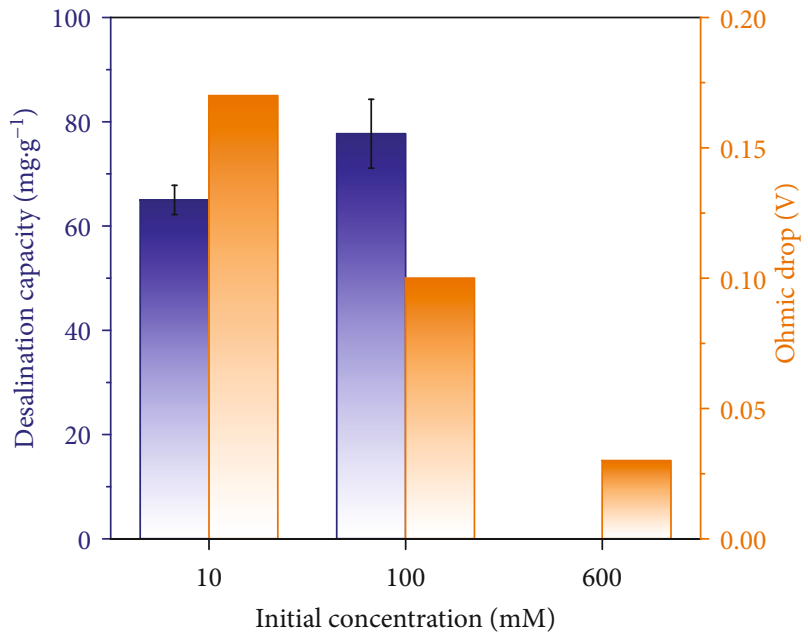

(c)

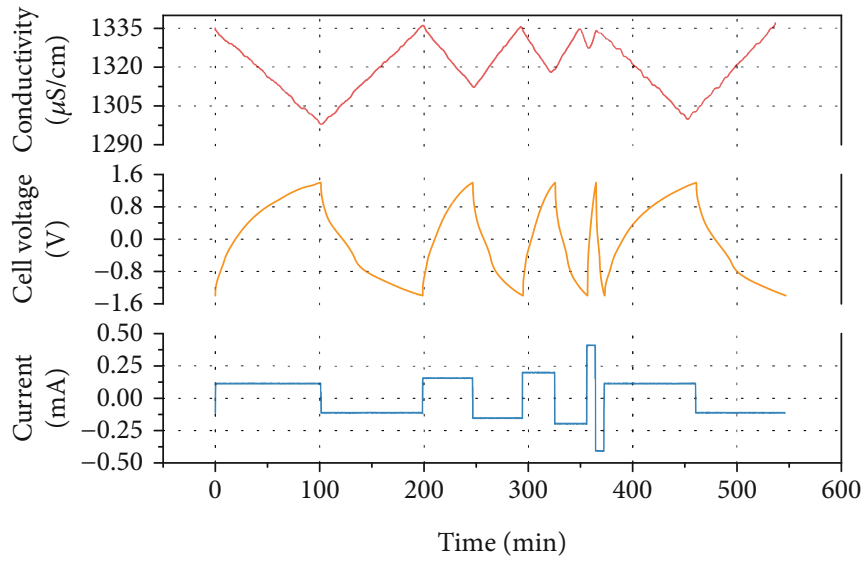

(b)

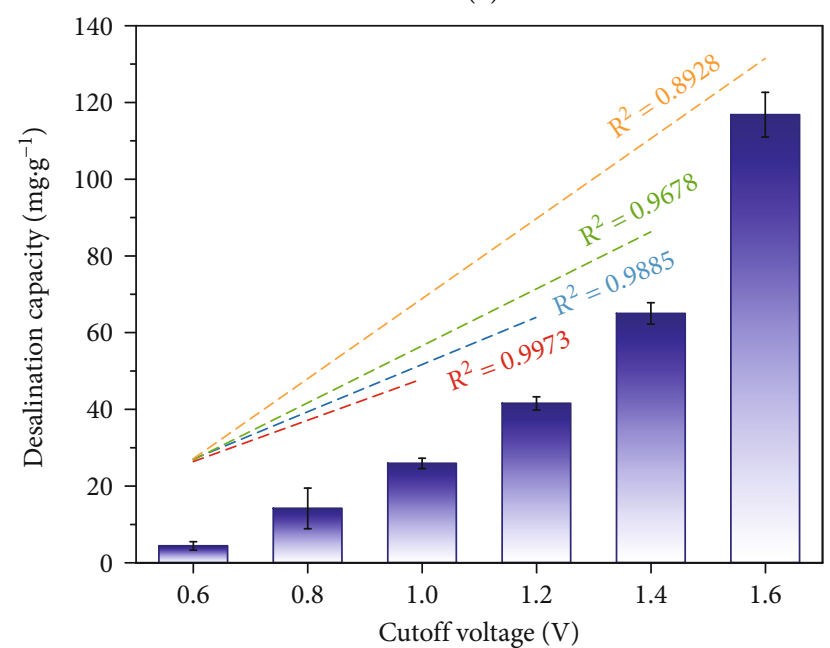

(d)

FIgURE 4: (a) Desalination capacity and desalination rate at different specific currents (initial NaCl concentration: $10 \mathrm{mM}$; cutoff voltage: $\pm 1.4 \mathrm{~V}$ ). (b) Recorded profiles of the conductivity, cell voltage, and current data at different rates $\left(30 / 40 / 50 / 100 / 30 \mathrm{~mA} \cdot \mathrm{g}^{-1}\right)$. (c) Desalination capacity and ohmic drop at different initial $\mathrm{NaCl}$ concentrations (specific current: $30 \mathrm{~mA} \cdot \mathrm{g}^{-1}$; cutoff voltage: $\pm 1.4 \mathrm{~V}$ ). (d) Desalination capacity with changing cutoff voltages and the correlation between capacity and cutoff voltage (initial concentration: $10 \mathrm{mM}$; specific current: $30 \mathrm{~mA} \cdot \mathrm{g}^{-1}$ ).

To better predict the performance during deionization, we carried out experiments in a two-electrode configuration (Supporting Information, Fig. S4). The cyclic voltammograms show some broad redox peaks as the indicator of the valence change between $\mathrm{Co}^{2+}$ and $\mathrm{Co}^{3+}$. The electrode polarization occurs when the cell voltage exceeds $0.8 \mathrm{~V}$, which might be due to slight carbon oxidation and water hydrolysis. The charging capacity at different rates $\left(40-1000 \mathrm{~mA} \cdot \mathrm{g}^{-1}\right)$ changes moderately from $35 \mathrm{mAh} \cdot \mathrm{g}^{-1}$ to $21 \mathrm{mAh} \cdot \mathrm{g}^{-1}$. This behavior is like what was observed during cyclic voltammetry. The h-Co $(\mathrm{OH})_{2}$ electrodes provide an excellent rate capability and stability, projecting to have relatively high deionization capacity and good durability, and the reaction equation of $\mathrm{Na}^{+}$capture is stated as follows in Equations (2) and (3) $[11,31]$.

$$
\begin{gathered}
\mathrm{CoOOH}+x \mathrm{e}^{-}+x \mathrm{Na}^{+} \longrightarrow \mathrm{Co}(\mathrm{OH})_{2} \mathrm{Na}_{x} \\
\mathrm{Co}(\mathrm{OH})_{2}(\mathrm{OH})_{x}{ }^{-}+x \mathrm{Na}^{+} \longrightarrow \mathrm{Co}(\mathrm{OH})_{2}(\mathrm{OH})_{x} \mathrm{Na}_{x}
\end{gathered}
$$

3.3. Desalination Performance. Hybrid capacitive deionization (HCDI) cell is applied to evaluate the desalination performance of $\mathrm{h}-\mathrm{Co}(\mathrm{OH})_{2}$ under various conditions, and this classical configuration adopts ion exchange membranes to strengthen the charge efficiency and oxygen penetration. The specific current is a vital operational parameter, especially for engineering practices, closely related to desalination efficiency and energy consumption. The desalination capacity is $107 \pm 3 \mathrm{mg}(\mathrm{NaCl}) \cdot \mathrm{g}^{-1}\left(\mathrm{~h}-\mathrm{Co}(\mathrm{OH})_{2}\right)$ at a rate of $30 \mathrm{~mA} \cdot \mathrm{g}^{-}$ ${ }^{1}$, and the capacity declines as the specific current increases to $100 \mathrm{~mA} \cdot \mathrm{g}^{-1}$ (Figure $4(\mathrm{a})$ ). Higher values of the specific current result in a shorter charging time and greater diffusion limit, and fewer active sites are available, leading to lower capacity (Figure 4(b)). As the specific current returns to the original level, the capacity is mostly restored [45], as shown in Supporting Information, Fig. S5. A higher specific current translates to a faster charge transfer, resulting in a higher desalination rate, and this value is $3.3 \mathrm{mg} \cdot \mathrm{g}^{-1} \cdot \mathrm{min}^{-1}$ at $100 \mathrm{~mA} \cdot \mathrm{g}^{-1}$, almost three times more than the rate at $30 \mathrm{~mA} \cdot \mathrm{g}^{-1}$ (Figure $4(\mathrm{a})$ ). The energy consumption increases 
with a higher specific current, confirmed by lower charge efficiency, which drops to $93 \%$ at $100 \mathrm{~mA} \cdot \mathrm{g}^{-1}$ (Supporting Information, Fig. S6).

The $\mathrm{NaCl}$ concentration also affects the desalination capacity, increasing from $65 \pm 3 \mathrm{mg} \cdot \mathrm{g}^{-1}$ to $78 \pm 7 \mathrm{mg} \cdot \mathrm{g}^{-1}$ when the $\mathrm{NaCl}$ feedwater concentration increases from $10 \mathrm{mM}$ to $100 \mathrm{mM}$ (Figure 4(c) and Supporting Information, Fig. S7A). The positive effect of increasing $\mathrm{NaCl}$ concentration can be explained by declining ohmic drop, and this value derived from the voltage profile is $0.17 \mathrm{~V}, 0.1 \mathrm{~V}$, and $0.03 \mathrm{~V}$ for $10 \mathrm{mM}, 100 \mathrm{mM}$, and $600 \mathrm{mM} \mathrm{NaCl}$, respectively (Figure 4(c)).

The desalination capacity increases from $4 \pm 1 \mathrm{mg} \cdot \mathrm{g}^{-1}$ to $65 \pm 3 \mathrm{mg} \cdot \mathrm{g}^{-1}$ when the voltage range expands from $-0.6 \mathrm{~V} /+0.6 \mathrm{~V}$ to $-1.4 \mathrm{~V} /+1.4 \mathrm{~V}$ (Figure $4(\mathrm{~d})$ and Supporting Information, Fig. S7B). Broader voltage intervals correspond with prolonged charging times, as shown in Supporting Information, Fig. S8. Thus, more charge is accumulated at the electrode to participate in the desalination process. Some of the invested charge is consumed due to the internal cell resistance (intrinsic electrode resistance, electrode-solution contact resistance, and electrolyte resistance), and therefore, the capacity under $-0.6 \mathrm{~V} /+0.6 \mathrm{~V}$ is small. When the voltage is further widened to $-1.6 \mathrm{~V} /+1.6 \mathrm{~V}$, the desalination capacity reaches $117 \pm 6 \mathrm{mg} \cdot \mathrm{g}^{-1}$. As shown in the CDI Ragone plot (known as Kim-Yoon plot; Supporting Information, Fig. S9), h- $\mathrm{Co}(\mathrm{OH})_{2}$ shows better desalination performance than commercial $\mathrm{Co}(\mathrm{OH})_{2}$ nanosheet, proving the positive effect of hollow configuration. Moreover, h- $\mathrm{Co}(\mathrm{OH})_{2}$ presents higher capacity than pure $\mathrm{Co}(\mathrm{OH})_{2}$ on graphite paper $\left(48 \mathrm{mg} \cdot \mathrm{g}^{-1}\right)$ and interconnected hollow graphene shell $\left(14 \mathrm{mg}^{-1} \mathrm{~g}^{-1}\right)$ proposed recently $[29,46]$.

A large effective surface area estimated to be around $179.8 \mathrm{~m}^{2} \cdot \mathrm{g}^{-1}$, over the value from $\mathrm{N}_{2}$ adsorption, is required if all $\mathrm{Na}^{+}$is adsorbed at the external surface of $h-\mathrm{Co}(\mathrm{OH})_{2}$ [47]. This rough deduction indicates that the subsurface also participates in deionization, underscoring the pseudocapacitive property. The relationship between average capacity and cutoff voltage is matched well by linear regression (Figure 4(d)), while the linear fit yields a larger deviation from the linear correlation at higher voltages as Faradaic side reactions intensify at $1.6 \mathrm{~V}$ [48].

Furthermore, 100 desalination cycles were carried out to characterize the performance stability of h-Co(OH $)_{2}$ electrodes. The average desalination capacity is about $70 \mathrm{mg} \cdot \mathrm{g}^{-}$ ${ }^{1}$, with a retention of $92 \%$ (Figure 5(a)). Compared with other carbon-metal composite electrodes, h-Co $(\mathrm{OH})_{2}$ exhibits a high capacity and good stability simultaneously (Figure 5(b)). Besides, the desalination rate of h- $\mathrm{Co}(\mathrm{OH})_{2}$ electrode is comparable to or even higher than advanced Faradic materials proposed recently (Supporting Information, Table S1). Subsequently, the electrochemical properties were also characterized after desalination. Cyclic voltammograms and galvanostatic charge/discharge profiles after desalination at different cutoff voltages and specific currents are analogous to raw electrodes except for minor peak alteration at around $-0.3 \mathrm{~V}$. Electrochemical impedance spectra exhibit similar internal ohmic resistance and charge-transfer resistance (Supporting Information,
Fig. S10). The electrodes, after desalination at different rates, display slightly higher capacitance and smaller charge-transfer resistance. Therefore, $\mathrm{h}-\mathrm{Co}(\mathrm{OH})_{2}$ electrodes demonstrate good electrochemical stability. Apart from $\mathrm{Na}^{+}$removal, h-Co $(\mathrm{OH})_{2}$ is possible to intercalate $\mathrm{Cl}^{-}$by applying $\mathrm{h}-\mathrm{Co}(\mathrm{OH})_{2}$ as an anode, supported by its higher chlorine ion removal capacity compared with activated carbon (Supporting Information, Fig. S11-S15).

The stability of h- $\mathrm{Co}(\mathrm{OH})_{2}$ electrodes is further illustrated by in situ electrochemical dilatometry, an indicator of volume change during sodiation/desodiation process and applied in two-dimensional $\mathrm{Ti}_{3} \mathrm{C}_{2}$-type MXene, and the schematic illustration of a dilatometer is presented in Supporting Information, Fig. S16 $[27,54,55]$. To match the voltage window vs. $\mathrm{Ag} / \mathrm{AgCl}$, the voltage range was set as $-0.8 \mathrm{~V}$ to $+0.3 \mathrm{~V}$ (vs. carbon), and $1 \mathrm{M} \mathrm{Na}_{2} \mathrm{SO}_{4}$ electrolyte was used to avoid chlorine-related corrosion of the apparatus. Before testing, the cell was stabilized for $48 \mathrm{~h}$, and over $80 \%$ of the electrode displacement occurs at the initial $4 \mathrm{~h}$ $\left(1^{\text {st }}\right.$ to $7^{\text {th }}$ cycle), following the decay trend displayed in long-cycle desalination (Figure 5(c)). The drop in the displacement may align with the partial disintegration of hollow $\mathrm{Co}(\mathrm{OH})_{2}$ cubes. The displacement remains almost unchanged afterward, suggesting that the $h-\mathrm{Co}(\mathrm{OH})_{2}$ electrode has minimal volume change during salination/desalination. Figure 5(d) displays cyclic voltammograms, which were recorded during the in situ dilatometry. The shape of the cyclic voltammogram of the h- $\mathrm{Co}(\mathrm{OH})_{2}$ electrodes closely matched with what was recorded in a typical standard three-electrode test cell. All obtained electrochemical features are similar to those of the cyclic voltammetry results presented before, even though the current is comparably low in the dilatometry cell. Their shape remains stable after the third cycle. Correspondingly, the relative strain becomes negligible (the original data of relative strain is presented in Supporting Information, Fig. S17A), demonstrating that the hollow structure relieves the stress from volume change appropriately. To exclude the influence of the stabilization period, the system was tested after stabilizing for $72 \mathrm{~h}$. The relative strain tends to be stable, and the relative strain becomes zero after the $10^{\text {th }}$ cycle (Supporting Information, Fig. S17B). Therefore, electrochemical dilatometry proves that the hollow h-Co $(\mathrm{OH})_{2}$ structure can relieve the electrode volume change to enhance the stability after the desalination has reached equilibrium.

3.4. Desalination Mechanism. The intrinsic pseudocapacitance provides maximum synergy with the fast ion transport via the porous $3 \mathrm{D}$ architecture of the hollow $\mathrm{Co}(\mathrm{OH})_{2}$ cubes. These beneficial electrochemical properties result in a high desalination capacity and good stability. A kinetic analysis can further investigate the charge storage and ion removal kinetics. Specifically, one can derive key information via analysis of the dependency of the measured current with the sweep rate [56], stated in equations (4) and (5).

$$
\begin{gathered}
i=a v^{b}, \\
\log (i)=b \log (v)+\log (a) .
\end{gathered}
$$




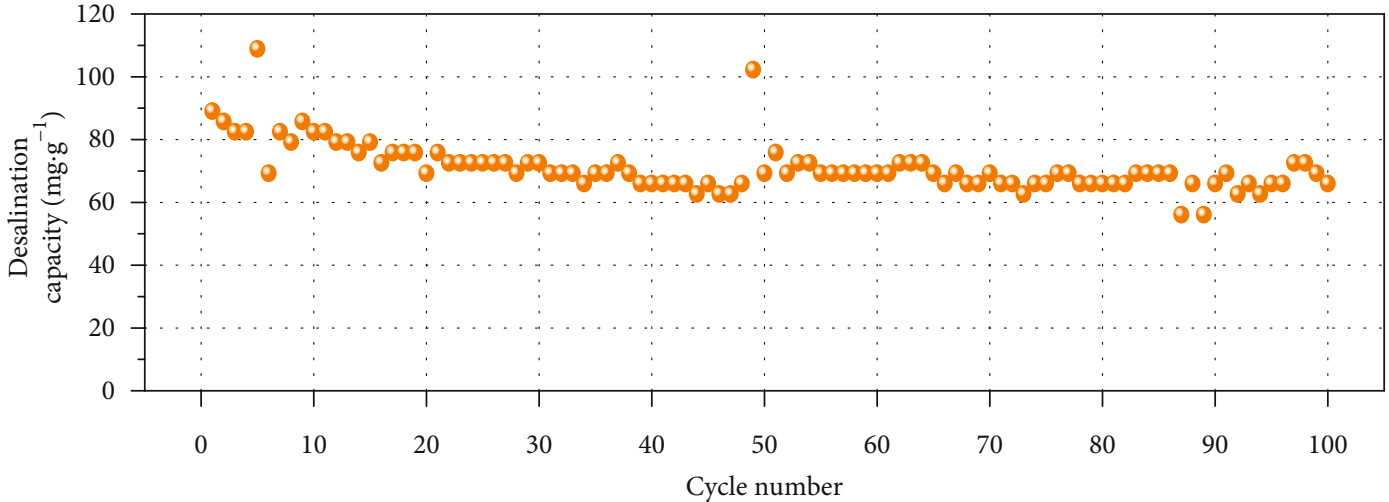

(a)

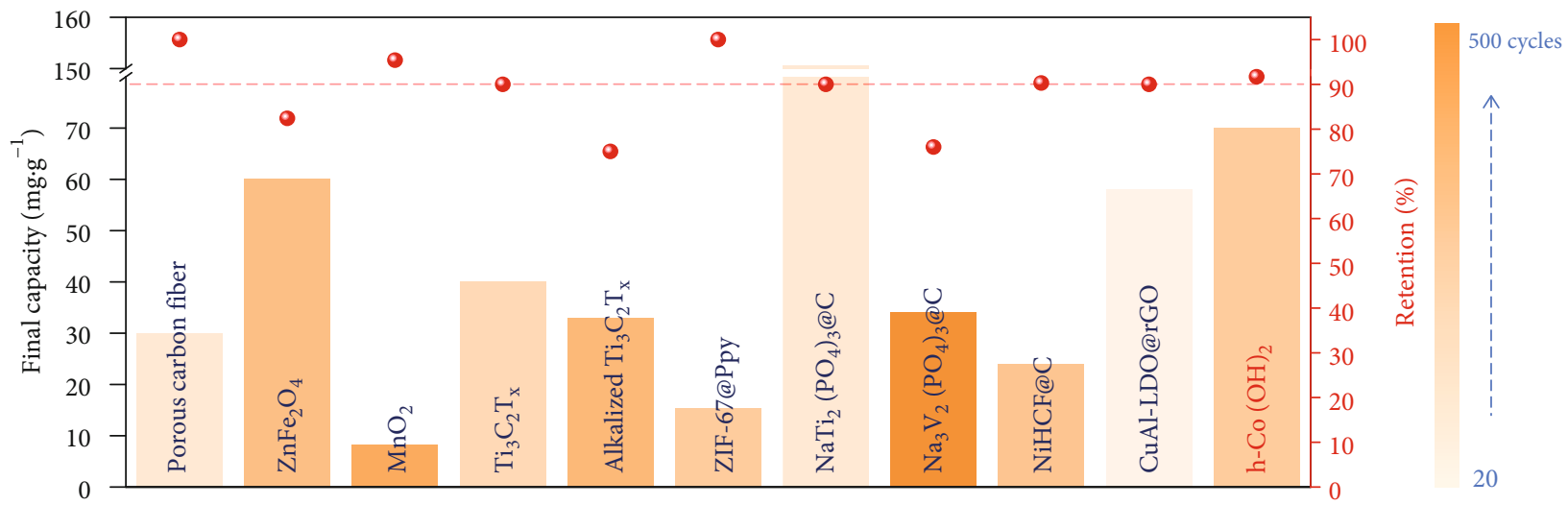

(b)

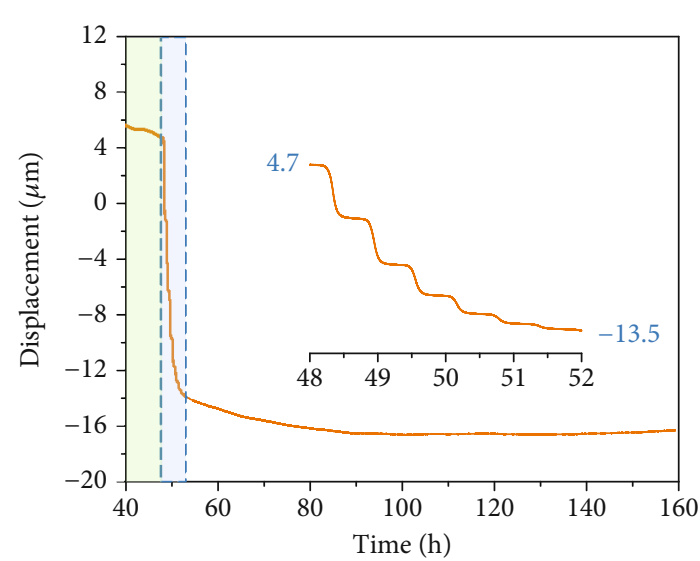

48 h stabilization

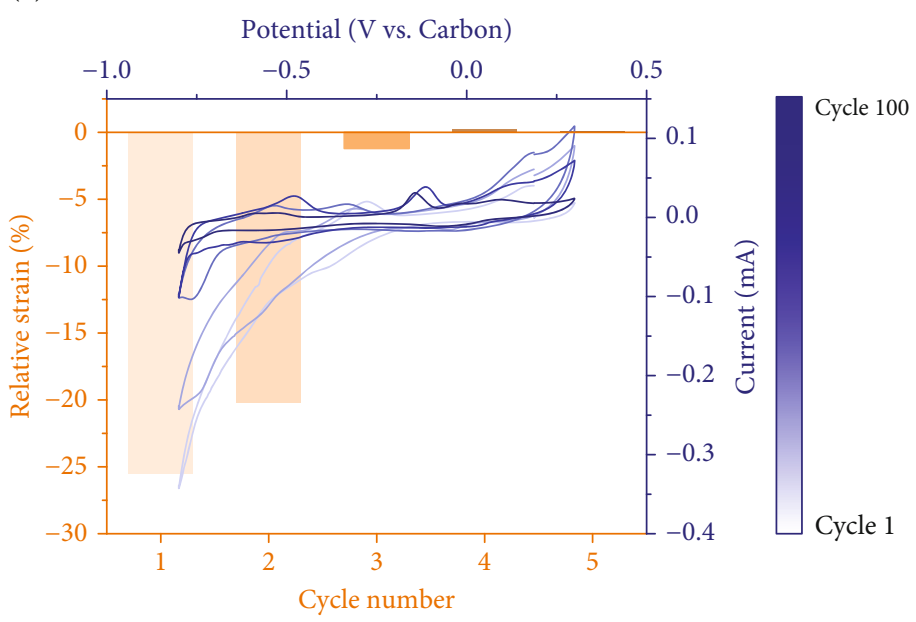

(d)

FIGURE 5: (a) Desalination capacity of HCDI cell for 100 cycles (specific current: $30 \mathrm{~mA} \cdot \mathrm{g}^{-1}$; cutoff voltage: $\pm 1.2 \mathrm{~V}$; initial NaCl concentration: $10 \mathrm{mM}$ ). (b) Stability comparison of various electrode materials considering final capacity, retention rate, and cycle number (a different color represents the cycle number) [11, 16, 17, 27, 47, 49-53]. (c) h-Co(OH) $)_{2}$ electrode displacement development during in situ electrochemical dilatometry in CV mode, and the inset is the magnified diagram for the initial $4 \mathrm{~h}$. (d) Cyclic voltammograms and relative strain at the $1^{\text {st }}, 3^{\text {rd }}, 10^{\text {th }}, 50^{\text {th }}$, and $100^{\text {th }}$ cycle.

The $b$-value can be determined from the plot's slope between $\log (i)$ and $\log (v)$ and indicates the charge storage mechanism. When the $b$-value is 0.5 , we have a system limited by diffusion, as typically found for battery-like systems via ion intercalation. In contrast, a $b$-value of 1.0 is found for an ideal capacitor, such as an electrical double-layer capacitor, where charge storage is enabled via ion electrosorption. According to Figure 6(a), the calculated $b$-values exceed 0.8 when the voltage is lower than $0.3 \mathrm{~V}$. This very high value aligns with the pronounced pseudocapacitive 


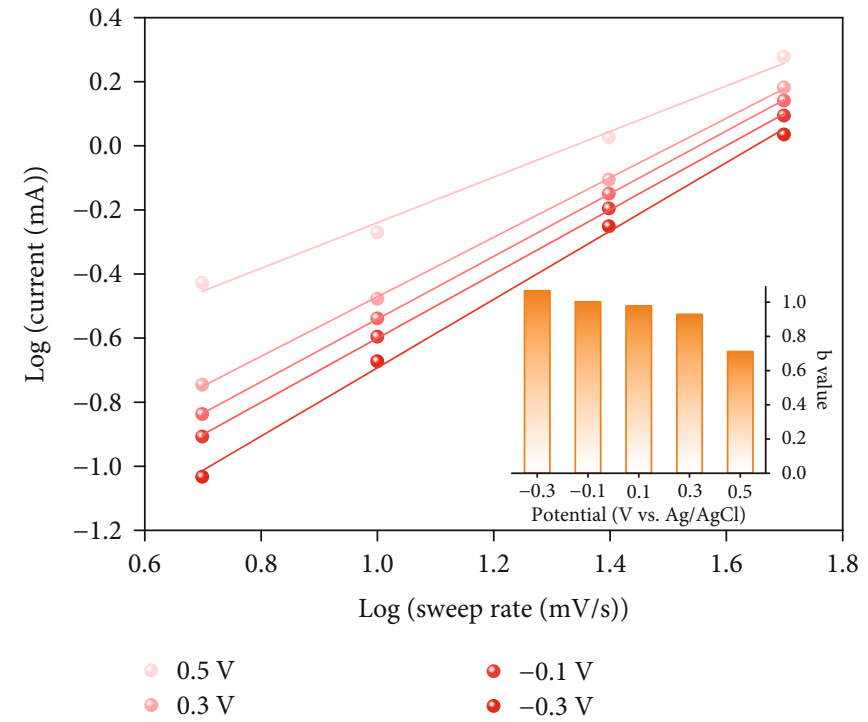

(a)

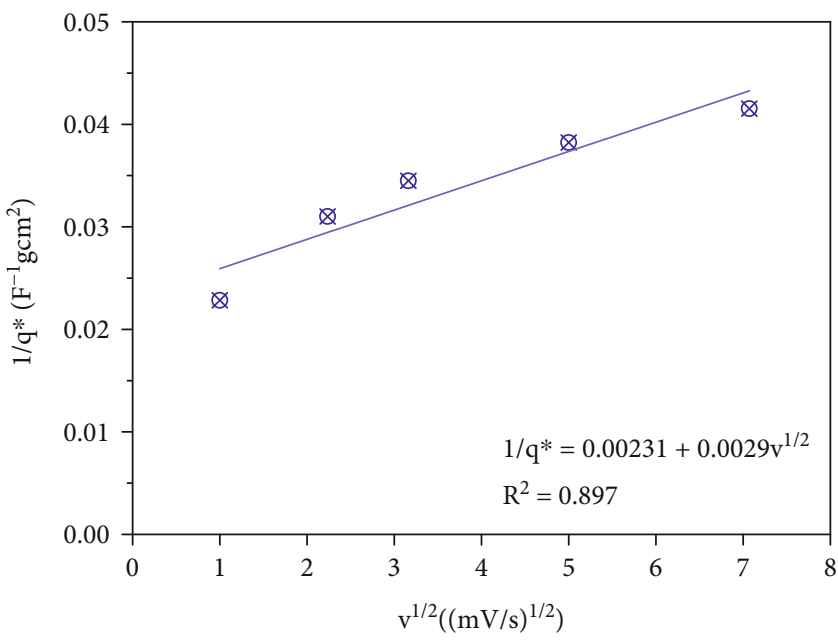

(c)

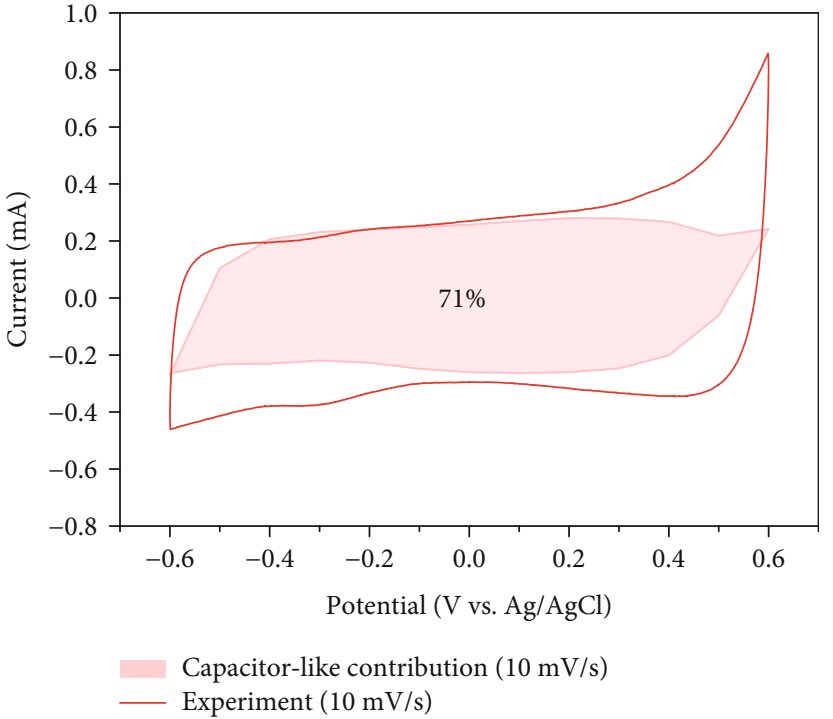

(b)

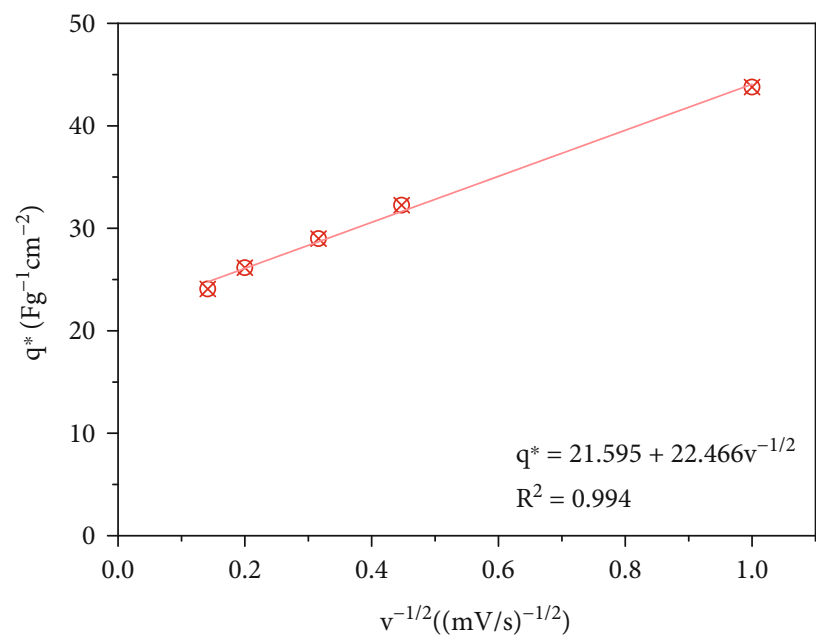

(d)

Figure 6: (a) Calculation of $b$-values based on CV curves. (b) Estimation of pseudocapacitive contribution of the cyclic voltammogram at $10 \mathrm{mV} \cdot \mathrm{s}^{-1}$. (c) The relationship between $1 / q^{*}$ and $v^{1 / 2}$. (d) The relationship between $q^{*}$ and $v^{-1 / 2}$.

behavior of the electrode material. The $b$-value drops to about 0.7 at $0.5 \mathrm{~V}$, which agrees with the more battery-like process through $\mathrm{Na}^{+}$intercalation and side reactions. This also aligns with the findings from the performance stability measurements via continued cyclic voltammetric testing.

It is also possible to quantify the percentage of surfacecontrolled capacitance (capacitor-like contribution) corresponding with either a perfect diffusion-limited system ( $b$-value of 0.5$)$ or a perfect capacitor ( $b$-value of 1.0). The closer it is to one, the more perfect is the pseudocapacitive response. A beneficial calculation for this consideration is the use of Equation (6) which is often referred to as Dunn analysis [44]:

$$
i(V)=k_{1} v+k_{2} v^{1 / 2} .
$$

In this equation, $k_{1}$ corresponds with an ideal (pseudo)capacitive contribution and $k_{2}$ with a battery-like feature.
For our electrode material, $k_{1}$ represents $71 \%$ of the total capacity at the scan rate of $10 \mathrm{mV} \cdot \mathrm{s}^{-1}$ (Figure 6(b)). As a comparison, this percentage for a recently reported black phosphorus composite is $59 \%$ at $5 \mathrm{mV} \cdot \mathrm{s}^{-1}$ [57].

An alternative analysis is the Trasatti method. This approach differentiates an "inner" and "outer" surfacecontrolled capacity of h- $\mathrm{Co}(\mathrm{OH})_{2}$ electrode [58]. To be specific, "inner" surface refers to the regions of difficult accessibility, and "outer" capacity mainly comes from the surface exposed directly to ions. The calculation is based on Equations (7) and (8) [44].

$$
\begin{gathered}
q^{*}=q_{\mathrm{s}, \mathrm{out}}+A_{1} v^{-1 / 2}, \\
q^{*-1}=q_{\mathrm{s}}^{-1}+A_{2} v^{1 / 2} .
\end{gathered}
$$

where $q^{*}$ is the voltammetric charge, $q_{\mathrm{s}}$ is the surfacecontrolled capacity, and $q_{\mathrm{s}, \text { out }}$ is the "outer" capacity. $q_{\mathrm{s}, \text { out }}$ 


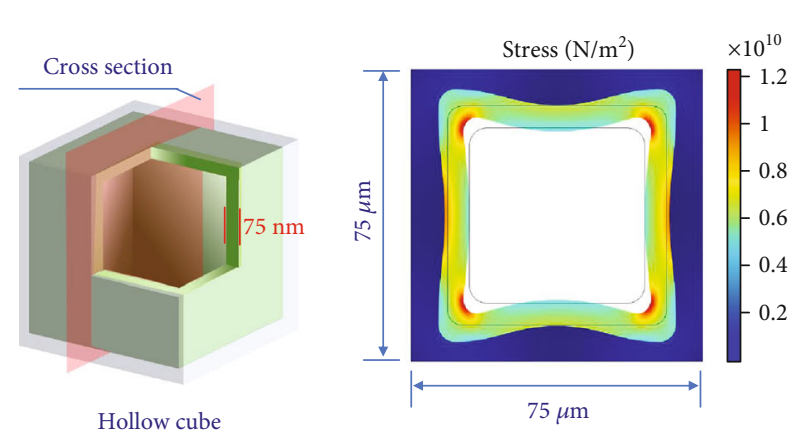

(a)

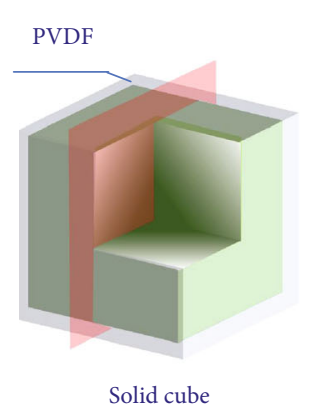

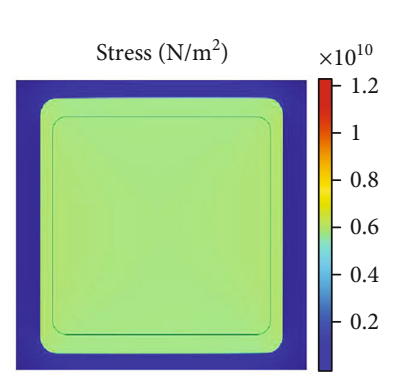

(d)

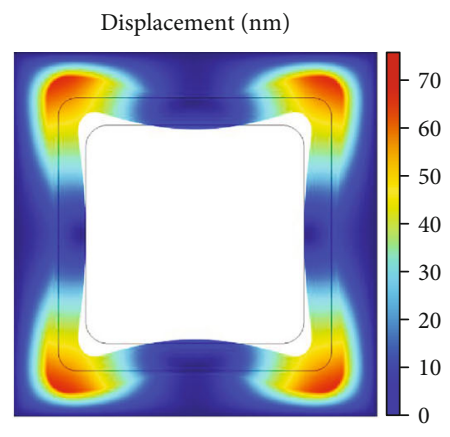

(b)

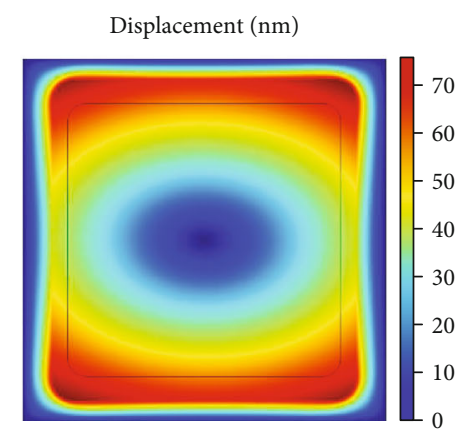

(e)

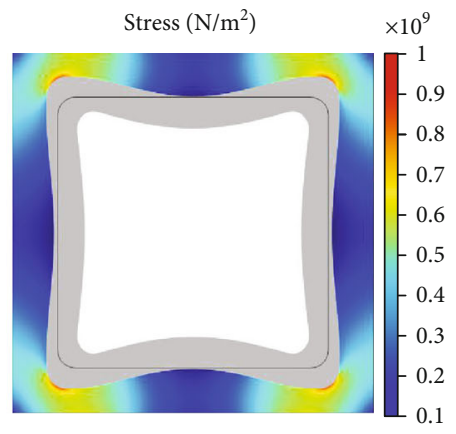

(c)

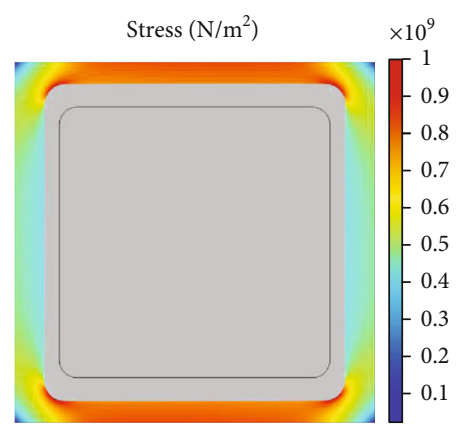

(f)

FIGURE 7: Finite element simulation results of stress and deformation displacement distribution in a hollow cube (a, b) and solid cube (d, e) at a fixed volume expansion percentage. Finite element simulation results of stress distribution in surrounding adhesive PVDF of a hollow cube (c) and solid cube (f).

is calculated to be $22 \mathrm{~F} \cdot \mathrm{g}^{-1} \cdot \mathrm{cm}^{-2}$, constituting $50 \%$ of $q_{\mathrm{s}}$, which is comparable to modified carbon electrodes [59] and notably higher than CuAl-LDH@rGO [53]. This indicates that hollow $\mathrm{Co}(\mathrm{OH})_{2}$ electrode provides rapid, capacitorlike charge transfer and ion removal (Figures 6(c) and 6(d)).

To further elaborate the cushion effect of hollow configuration during ion intercalation, finite element simulation was carried out to investigate and compare the stress distribution in hollow and solid cubes after volume expansion; detailed simulation information is given in Supporting Information, Text S1). Finite element simulation is applied to analyze the ion concentration distribution during desalination and to demonstrate that a hollow structure is favorable for ion transport $[60,61]$. Based on in situ dilatometry, the expansion proportion is fixed at $40 \%$ for both structures. For a solid cube, the stress inside the materials is homogeneous at about $0.6 \times 10^{10} \mathrm{~N} / \mathrm{m}^{2}$ after electrochemical volume expansion (Figure $7(\mathrm{~d})$ ), while the stress in a hollow cube is heterogeneous. Edges (especially top and bottom edges) of the two-dimensional hollow cross section generally display more minor stress at around $0.4 \times 10^{10} \mathrm{~N} / \mathrm{m}^{2}$. More significant stress $\left(1 \times 10^{10} \mathrm{~N} / \mathrm{m}^{2}\right)$ occurs at the corner (Figure 7(a)) due to stress from adjacent edges and induced shear stress during $\mathrm{Na}^{+}$intercalation. During expansion, the physical deformation of materials is expressed as displacement, that is, bias relative to the initial position. The displacement in a hollow cube is generally smaller, and the maximum value is approximately $60 \mathrm{~nm}$ (Figure $7(\mathrm{~b})$ ). Contrarily, half of the solid cube experiences remarkable displacement with the maximum deformation of $70 \mathrm{~nm}$ (Figure 7(e)). Therefore, the hollow structure is more stable as it undergoes less distortion and stress when charging, except for higher stress at the corner.

The stress distribution of wrapped binder PVDF is studied to reflect the complete working condition of the electrode. The PVDF around the hollow cube exhibits stress at a scale of $0.2 \times 10^{9} \mathrm{~N} / \mathrm{m}^{2}$ (Figure $7(\mathrm{c})$ ), which is generally smaller than the solid cube counterpart $\left(0.9 \times 10^{9} \mathrm{~N} / \mathrm{m}^{2}\right.$ at top and bottom edges; Figure 7(f)). The hollow structure exerts minor stress to surrounding binder material, conducive to keep the whole electrode intact during electrochemical ion intercalation by relieving the accompanying stress.

\section{Conclusions}

In summary, a hollow pseudocapacitive cobalt hydroxide was prepared via facile synthesis conditions. The hollow $\mathrm{Co}(\mathrm{OH})_{2}$ cube with vertical nanosheets anchored on the surface has a large ion accessible surface area based on electrochemical analyses, ensuring fast ion transport. Meanwhile, this configuration can relieve the pressure during ion intercalation to enhance the cyclability, proved by finite element simulation. Consequently, h- $\mathrm{Co}(\mathrm{OH})_{2}$ electrode displays a high desalination rate of $3.3 \mathrm{mg}(\mathrm{NaCl}) \cdot \mathrm{g}^{-1}\left(\mathrm{~h}-\mathrm{Co}(\mathrm{OH})_{2}\right) \cdot-$ $\mathrm{min}^{-1}$ at $100 \mathrm{~mA} \cdot \mathrm{g}^{-1}$ and sustains over $90 \%$ of the initial capacity after 100 desalination cycles in HCDI cell. Moreover, this hollow electrode holds high capacity intrinsically by avoiding "dead mass," with the maximum value of 
$117 \pm 6 \mathrm{mg}(\mathrm{NaCl}) \cdot \mathrm{g}^{-1}\left(\mathrm{~h}-\mathrm{Co}(\mathrm{OH})_{2}\right)$. The outstanding desalination performance of the hollow structure in the microscale navigates a new direction to the development of Faradaic electrodes for CDI.

\section{Data Availability}

The .txt or .jpeg data used to support the findings of this study are available from the corresponding author upon request.

\section{Conflicts of Interest}

The authors declare that there are no conflicts of interest regarding the publication of this article.

\section{Authors' Contributions}

Yuecheng Xiong and Fei Yu contributed equally to this work.

\section{Acknowledgments}

This research was supported by the National Natural Science Foundation of China (52170087, 21777118). The INM authors thank Eduard Arzt (INM) for his continuing support. L.W. acknowledges funding from the China Scholarship Council (CSC) via award number 201906260277.

\section{Supplementary Materials}

Fig. S1: transmission electron micrographs of $\mathrm{Cu}_{2} \mathrm{O}$ template etching and $\mathrm{Co}(\mathrm{OH})_{2}$ crystal growth process. Fig. S2: water contact angle of the cobalt hydroxide electrode before (A) and after (B) desalination. Fig. S3: cyclic voltammogram of the cobalt hydroxide electrode at a rate of $1 \mathrm{mV} \cdot \mathrm{s}-1$. Fig. S4: (A) cyclic voltammograms of the cobalt hydroxide electrode at a rate of $10 \mathrm{mV} \cdot \mathrm{s}-1$ using a two electrode setup with an oversized AC electrode as counter electrode. (B) Cyclic voltammograms with different cutoff voltages. (C) Charging capacity of $\mathrm{Co}(\mathrm{OH})_{2}$ electrode in two electrode system with changing specific current. Fig. S5: desalination capacity (A), cell voltage profiles, (B) and current profiles (C) of the HCDI cell at different specific current. Fig. S6: energy consumption (A) and charge efficiency (B) at different rates. Fig. S7: (A) desalination capacity at $100 \mathrm{mM}$ initial $\mathrm{NaCl}$ concentration. (B) Desalination capacity of HCDI cell at different cutoff voltages. Fig. S8: voltage profiles of HCDI cell at different cutoff voltages. Fig. S9: Kim-Yoon plot of h- $\mathrm{Co}(\mathrm{OH})_{2}$ electrode in HCDI cell. Fig. S10: electrochemical characterizations for h- $\mathrm{Co}(\mathrm{OH})_{2}$ electrodes after desalination. Fig. S11: $\mathrm{CV}$ curves and capacitance of h- $\mathrm{Co}(\mathrm{OH}) 2$ electrode at different voltage windows. Fig. S12: de-chlorination performance. Fig. S13: (A) desalination capacity of symmetric CDI cell for 100 cycles. (B) Theoretical de-chlorination capacity of asymmetric and symmetric CDI cells for 100 cycles. Fig. S14: cell voltage (A) and current profiles (B) of asymmetric cell for 100 cycles. Fig. S15: cell voltage (A) and current profiles (B) of symmetric CDI cell for 100 cycles. Fig. S16: schematic drawing of the in-situ elec- trochemical dilatometry cell. Fig. S17: (A) the original data of relative strain during electro-dilatometry in $\mathrm{CV}$ mode. (B) The relative strain change in the test after $72 \mathrm{~h}$ stabilization. Table S1: comparison of desalination rate of various advanced electrode materials. Text S1: finite element simulation. (Supplementary Materials)

\section{References}

[1] M. Elimelech and W. A. Phillip, "The future of seawater desalination: energy, technology, and the environment," Science, vol. 333, no. 6043, pp. 712-717, 2011.

[2] R. P. Schwarzenbach, B. I. Escher, K. Fenner et al., "The challenge of micropollutants in aquatic systems," Science, vol. 313, no. 5790, pp. 1072-1077, 2006.

[3] F. A. AlMarzooqi, A. A. Al Ghaferi, I. Saadat, and N. Hilal, "Application of capacitive deionisation in water desalination: a review," Desalination, vol. 342, pp. 3-15, 2014.

[4] M. Metzger, M. M. Besli, S. Kuppan et al., "Techno-economic analysis of capacitive and intercalative water deionization," Energy \& Environmental Science, vol. 13, no. 6, pp. 15441560, 2020.

[5] S. Porada, R. Zhao, A. van der Wal, V. Presser, and P. M. Biesheuvel, "Review on the science and technology of water desalination by capacitive deionization," Progress in Materials Science, vol. 58, no. 8, pp. 1388-1442, 2013.

[6] X. Zhou, F. Zhao, Y. Guo, Y. Zhang, and G. Yu, "A hydrogelbased antifouling solar evaporator for highly efficient water desalination," Energy \& Environmental Science, vol. 11, no. 8, pp. 1985-1992, 2018.

[7] P. Srimuk, X. Su, J. Yoon, D. Aurbach, and V. Presser, "Charge-transfer materials for electrochemical water desalination, ion separation and the recovery of elements," Nature Reviews Materials, vol. 5, no. 7, pp. 517-538, 2020.

[8] B. W. Byles, D. A. Cullen, K. L. More, and E. Pomerantseva, "Tunnel structured manganese oxide nanowires as redox active electrodes for hybrid capacitive deionization," Nano Energy, vol. 44, pp. 476-488, 2018.

[9] M. Liang, X. Bai, F. Yu, and J. Ma, “A confinement strategy to in-situ prepare a peanut-like $\mathrm{N}$-doped, $\mathrm{C}$-wrapped $\mathrm{TiO}_{2}$ electrode with an enhanced desalination capacity and rate for capacitive deionization," Nano Research, vol. 14, no. 3, pp. 684-691, 2021.

[10] J. Lee, P. Srimuk, K. Aristizabal et al., "Pseudocapacitive desalination of brackish water and seawater with vanadiumpentoxide-decorated multiwalled carbon nanotubes," ChemSusChem, vol. 10, no. 18, pp. 3611-3623, 2017.

[11] J. Ma, Y. Xiong, X. Dai, and F. Yu, "Zinc spinel ferrite nanoparticles as a pseudocapacitive electrode with ultrahigh desalination capacity and long-term stability," Environmental Science \& Technology Letters, vol. 7, no. 2, pp. 118-125, 2020.

[12] Z. Ding, X. Xu, Y. Li, K. Wang, T. Lu, and L. Pan, "Significantly improved stability of hybrid capacitive deionization using nickel hexacyanoferrate/reduced graphene oxide cathode at low voltage operation," Desalination, vol. 468, article 114078, 2019.

[13] S. Porada, A. Shrivastava, P. Bukowska, P. M. Biesheuvel, and K. C. Smith, "Nickel hexacyanoferrate electrodes for continuous cation intercalation desalination of brackish water," Electrochimica Acta, vol. 255, pp. 369-378, 2017.

[14] K. Singh, Z. Qian, P. M. Biesheuvel, H. Zuilhof, S. Porada, and L. C. P. M. de Smet, "Nickel hexacyanoferrate electrodes for 
high mono/divalent ion-selectivity in capacitive deionization," Desalination, vol. 481, article 114346, 2020.

[15] J. Cao, Y. Wang, L. Wang, F. Yu, and J. Ma, “ $\mathrm{Na}_{3} \mathrm{~V}_{2}\left(\mathrm{PO}_{4}\right)_{3} @ \mathrm{C}$ as faradaic electrodes in capacitive deionization for highperformance desalination," Nano Letters, vol. 19, no. 2, pp. 823-828, 2019.

[16] W. Zhao, L. Guo, M. Ding, Y. Huang, and H. Y. Yang, "Ultrahigh-desalination-capacity dual-ion electrochemical deionization device based on $\mathrm{Na}_{3} \mathrm{~V}_{2}\left(\mathrm{PO}_{4}\right)_{3} @ \mathrm{C}$-AgCl electrodes," ACS Applied Materials \& Interfaces, vol. 10, no. 47, pp. 4054040548, 2018.

[17] K. Wang, Y. Liu, Z. Ding, Y. Li, T. Lu, and L. Pan, "Metalorganic-frameworks-derived $\mathrm{NaTi}_{2}\left(\mathrm{PO}_{4}\right)_{3}$ /carbon composites for efficient hybrid capacitive deionization," Journal of Materials Chemistry A, vol. 7, no. 19, pp. 12126-12133, 2019.

[18] P. Srimuk, F. Kaasik, B. Krüner et al., "MXene as a novel intercalation-type pseudocapacitive cathode and anode for capacitive deionization," Journal of Materials Chemistry A, vol. 4, no. 47, pp. 18265-18271, 2016.

[19] W. Bao, X. Tang, X. Guo et al., "Porous cryo-dried MXene for efficient capacitive deionization," Joule, vol. 2, no. 4, pp. 778$787,2018$.

[20] F. Xing, T. Li, J. Li, H. Zhu, N. Wang, and X. Cao, "Chemically exfoliated $\mathrm{MoS}_{2}$ for capacitive deionization of saline water," Nano Energy, vol. 31, pp. 590-595, 2017.

[21] P. Srimuk, J. Lee, A. Tolosa, C. Kim, M. Aslan, and V. Presser, "Titanium disulfide: a promising low-dimensional electrode material for sodium ion intercalation for seawater desalination," Chemistry of Materials, vol. 29, no. 23, pp. 9964-9973, 2017.

[22] P. Srimuk, J. Lee, S. Fleischmann et al., "Faradaic deionization of brackish and sea water via pseudocapacitive cation and anion intercalation into few-layered molybdenum disulfide," Journal of Materials Chemistry A, vol. 5, no. 30, pp. 1564015649, 2017.

[23] W. Shi, X. Liu, T. Deng et al., "Enabling superior sodium capture for efficient water desalination by a tubular polyaniline decorated with Prussian blue nanocrystals," Advanced Materials, vol. 32, no. 33, article e1907404, 2020.

[24] L. Xu, W. Liu, Y. Hu, and L. Luo, "Stress-resilient electrode materials for lithium-ion batteries: strategies and mechanisms," Chemical Communications, vol. 56, no. 87, pp. 13301-13312, 2020.

[25] M. Zheng, H. Tang, L. Li et al., "Hierarchically nanostructured transition metal oxides for lithium-ion batteries," Advanced Science, vol. 5, no. 3, article 1700592, 2018.

[26] W. Zhao, M. Ding, L. Guo, and H. Y. Yang, "Dual-ion electrochemical deionization system with binder-free aerogel electrodes," Small, vol. 15, no. 9, article 1805505, 2019.

[27] Z. Wang, X. Xu, J. Kim et al., "Nanoarchitectured metalorganic framework/polypyrrole hybrids for brackish water desalination using capacitive deionization," Materials Horizons, vol. 6, no. 7, pp. 1433-1437, 2019.

[28] M. Xiao, Z. Wang, M. Lyu et al., "Hollow nanostructures for photocatalysis: advantages and challenges," Advanced Materials, vol. 31, no. 38, article e1801369, 2019.

[29] Y. Zhu, G. Zhang, C. Xu, and L. Wang, "Interconnected graphene hollow shells for high-performance capacitive deionization," ACS Applied Materials \& Interfaces, vol. 12, pp. 2970629716, 2020.
[30] J. Jiang, J. Liu, R. Ding et al., "Large-scale uniform $\alpha-\mathrm{Co}(\mathrm{OH}) 2$ Long nanowire arrays grown on graphite as pseudocapacitor electrodes," ACS Applied Materials \& Interfaces, vol. 3, no. 1, pp. 99-103, 2011.

[31] L. Wang, Z. H. Dong, Z. G. Wang, F. X. Zhang, and J. Jin, "Layered $\alpha-\mathrm{Co}(\mathrm{OH}) 2$ Nanocones as electrode materials for pseudocapacitors: understanding the effect of interlayer space on electrochemical activity," Advanced Functional Materials, vol. 23, no. 21, pp. 2758-2764, 2013.

[32] Z. Cai, L. Li, Y. Zhang et al., "Amorphous nanocages of $\mathrm{Cu}-$ $\mathrm{Ni}-\mathrm{Fe}$ hydr(oxy)oxide prepared by photocorrosion for highly efficient oxygen evolution," Angewandte Chemie (International Ed. in English), vol. 58, no. 13, pp. 41894194, 2019.

[33] J. Yu, J. Xiao, A. Li et al., "Enhanced multiple anchoring and catalytic conversion of polysulfides by amorphous MoS3Nanoboxes for high-performance Li-S batteries," Angewandte Chemie (International Ed. in English), vol. 59, no. 31, pp. 13071-13078, 2020.

[34] J. Nai, Y. Tian, X. Guan, and L. Guo, "Pearson's principle inspired generalized strategy for the fabrication of metal hydroxide and oxide nanocages," Journal of the American Chemical Society, vol. 135, no. 43, pp. 16082-16091, 2013.

[35] J. Liu, J. Nai, T. You et al., "The flexibility of an amorphous cobalt hydroxide nanomaterial promotes the electrocatalysis of oxygen evolution reaction," Small, vol. 14, no. 17, article e1703514, 2018.

[36] H. B. Li, P. Liu, Y. Liang, J. Xiao, and G. W. Yang, “Amorphous cobalt hydroxide nanostructures and magnetism from green electrochemistry," RSC Advances, vol. 3, no. 48, article 26412, 2013.

[37] J. Yang, H. Liu, W. N. Martens, and R. L. Frost, "Synthesis and characterization of cobalt hydroxide, cobalt oxyhydroxide, and cobalt oxide nanodiscs," Journal of Physical Chemistry C, vol. 114, no. 1, pp. 111-119, 2010.

[38] S. R. Shieh and T. S. Duffy, "Raman spectroscopy of $\mathrm{Co}(\mathrm{OH})_{2}$ at high pressures: implications for amorphization and hydrogen repulsion," Physical Review B, vol. 66, no. 13, 2002.

[39] J. Liu, J. Ke, Y. Li et al., " $\mathrm{Co}_{3} \mathrm{O}_{4}$ quantum dots/ $\mathrm{TiO}_{2}$ nanobelt hybrids for highly efficient photocatalytic overall water splitting," Applied Catalysis B: Environmental, vol. 236, pp. 396403, 2018.

[40] I. M. Alibe, K. A. Matori, H. A. A. Sidek et al., "Effects of polyvinylpyrrolidone on structural and optical properties of willemite semiconductor nanoparticles by polymer thermal treatment method," Journal of Thermal Analysis and Calorimetry, vol. 136, pp. 2249-2268, 2018.

[41] C. Li, C. Liu, W. Wang et al., "Towards flexible binderless anodes: silicon/carbon fabrics via double-nozzle electrospinning," Chemical Communications, vol. 52, no. 76, pp. 1139811401, 2016.

[42] B. J. Tan, K. J. Klabunde, and P. M. A. Sherwood, "XPS studies of solvated metal atom dispersed (SMAD) catalysts. evidence for layered cobalt-manganese particles on alumina and silica," Journal of the American Chemical Society, vol. 113, no. 3, pp. 855-861, 1991.

[43] V. Augustyn, P. Simon, and B. Dunn, "Pseudocapacitive oxide materials for high-rate electrochemical energy storage," Energy \& Environmental Science, vol. 7, no. 5, p. 1597, 2014.

[44] S. Fleischmann, J. B. Mitchell, R. Wang et al., "Pseudocapacitance: from fundamental understanding to high power energy 
storage materials," Chemical Reviews, vol. 120, no. 14, pp. 6738-6782, 2020.

[45] M. E. Suss, S. Porada, X. Sun, P. M. Biesheuvel, J. Yoon, and V. Presser, "Water desalination via capacitive deionization: what is it and what can we expect from it?," Energy \& Environmental Science, vol. 8, no. 8, pp. 2296-2319, 2015.

[46] X. Wen, M. Zhao, D. Zhang, X. Ma, Z. Lin, and M. Ye, “An integrated large-scale and vertically aligned $\mathrm{Co}(\mathrm{OH})_{2}$ [email protected] paper electrode for high performance capacitive deionization of saline water," Desalination, vol. 470, article 114117, 2019.

[47] T. Liu, J. Serrano, J. Elliott et al., "Exceptional capacitive deionization rate and capacity by block copolymer-based porous carbon fibers," Science Advances, vol. 6, no. 16, 2020.

[48] Y. Li, Z. Ding, K. Wang et al., "Suppressing the oxygen-related parasitic reactions in $\mathrm{NaTi}_{2}\left(\mathrm{PO}_{4}\right)_{3}$-based hybrid capacitive deionization with cation exchange membrane," Journal of Colloid and Interface Science, vol. 591, pp. 139-147, 2021.

[49] T. Wu, G. Wang, S. Wang et al., "Highly stable hybrid capacitive deionization with a MnO2Anode and a positively charged cathode," Environmental Science \& Technology Letters, vol. 5, no. 2, pp. 98-102, 2018.

[50] X. Shen, Y. Xiong, R. Hai, F. Yu, and J. Ma, “All-MXene-based integrated membrane electrode constructed using $\mathrm{Ti}_{3} \mathrm{C}_{2} \mathrm{~T}_{\mathrm{x}}$ as an intercalating agent for high-performance desalination," Environmental Science \& Technology, vol. 54, no. 7, pp. 4554-4563, 2020.

[51] X. Shen, R. Hai, X. Wang et al., "Free-standing 3D alkalized $\mathrm{Ti}_{3} \mathrm{C}_{2} \mathrm{~T}_{\mathrm{x}} / \mathrm{Ti}_{3} \mathrm{C}_{2} \mathrm{~T}_{\mathrm{x}}$ nanosheet membrane electrode for highly efficient and stable desalination in hybrid capacitive deionization," Journal of Materials Chemistry A, vol. 8, no. 37, pp. 19309-19318, 2020.

[52] S. Wang, G. Wang, Y. Wang et al., "In situ formation of Prussian blue analogue nanoparticles decorated with threedimensional carbon nanosheet networks for superior hybrid capacitive deionization performance," ACS Applied Materials \& Interfaces, vol. 12, no. 39, pp. 44049-44057, 2020.

[53] W. Xi and H. Li, "Vertically-aligned growth of CuAl-layered double oxides on reduced graphene oxide for hybrid capacitive deionization with superior performance," Environmental Science. Nano, vol. 7, no. 3, pp. 764-772, 2020.

[54] D. Moreno, Y. Bootwala, W.-Y. Tsai et al., "In situ electrochemical dilatometry of phosphate anion electrosorption," Environmental Science \& Technology Letters, vol. 5, no. 12, pp. 745-749, 2018.

[55] N. Jäckel, B. Krüner, K. L. Van Aken et al., "Electrochemical in situ tracking of volumetric changes in two-dimensional metal carbides (MXenes) in ionic liquids," ACS Applied Materials \& Interfaces, vol. 8, no. 47, pp. 32089-32093, 2016.

[56] J. Wang, J. Polleux, J. Lim, and B. Dunn, "Pseudocapacitive contributions to electrochemical energy storage in $\mathrm{TiO}_{2}$ (anatase) nanoparticles," Journal of Physical Chemistry $C$, vol. 111, no. 40, pp. 14925-14931, 2007.

[57] H. Jin, S. Xin, C. Chuang et al., "Black phosphorus composites with engineered interfaces for high-rate high-capacity lithium storage," Science, vol. 370, no. 6513, pp. 192-197, 2020.

[58] S. Ardizzone, G. Fregonara, and S. Trasatti, "Inner" and "outer" active surface of $\mathrm{RuO}_{2}$ electrodes," Electrochimica Acta, vol. 35, no. 1, pp. 263-267, 1990.

[59] R. Niu, H. Li, Y. Ma, L. He, and J. Li, “An insight into the improved capacitive deionization performance of activated carbon treated by sulfuric acid," Electrochimica Acta, vol. 176, pp. 755-762, 2015.

[60] X. Zang, Y. Xue, W. Ni et al., "Enhanced electrosorption ability of carbon nanocages as an advanced electrode material for capacitive deionization," ACS Applied Materials \& Interfaces, vol. 12, no. 2, pp. 2180-2190, 2020.

[61] S. Vafakhah, G. J. Sim, M. Saeedikhani, X. Li, P. Valdivia y Alvarado, and H. Y. Yang, "3D printed electrodes for efficient membrane capacitive deionization," Nanoscale Advances, vol. 1, no. 12, pp. 4804-4811, 2019. 